\title{
Therapeutic benefit of Salmonella attributed to LPS and TNF-a is exhaustible and dictated by tumor susceptibility
}

\author{
Dino Kocijancic ${ }^{1}$, Sara Leschner ${ }^{1}$, Sebastian Felgner ${ }^{1}$, Ronja-Melinda Komoll ${ }^{1}$, \\ Michael Frahm ${ }^{1}$, Vinay Pawar $^{1}$, Siegfried Weiss ${ }^{1,2}$ \\ ${ }^{1}$ Department of Molecular Immunology, Helmholtz Centre for Infection Research, Braunschweig, Germany \\ ${ }^{2}$ Institute of Immunology, Medical School Hannover, Hannover, Germany
}

Correspondence to: Dino Kocijancic, email: dino.kocijancic@helmholtz-hzi.de

Keywords: TNF alpha, LPS, cancer immune therapy, salmonella, bacteria mediated tumor therapy

Received: June 15, $2016 \quad$ Accepted: March 29, $2017 \quad$ Published: April 06, 2017

Copyright: Kocijancic et al. This is an open-access article distributed under the terms of the Creative Commons Attribution License (CC-BY), which permits unrestricted use, distribution, and reproduction in any medium, provided the original author and source are credited.

ABSTRACT

The potential of bacteria-mediated tumor therapy (BMTT) is highlighted by more than a century of investigation. Attenuated Salmonella has prevailed as promising therapeutic agents. For BMTT - categorized as an immune therapy - the exact contribution of particular immune reactions to the therapeutic effect remains ambiguous. In addition, one could argue for or against the requirement of bacterial viability and tumor targeting. Herein we evaluate the isolated therapeutic efficacy of purified LPS and TNF-a, which together account for a dominant immunogenic pathway of gram negative bacteria like Salmonella. We show that therapeutic efficacy against CT26 tumors does not require bacterial viability. Analogous to viable Salmonella SL7207, tumor regression by a specific $\mathrm{CDB}^{+} \mathrm{T}$ cell response can be induced by purified LPS or recombinant TNF-a (rTNF-a). Conversely, therapeutic effects against RenCa tumors were abrogated upon bacterial avitalization and limited using isolated adjuvants. This argues for an alternative mechanistic explanation for SL7207 against RenCa that depends on viability and persistence. Unable to boost bacterial therapies by co-injection of rTNF-a suggested therapeutic effects along this axis are exhausted by the intrinsic adjuvanticity of bacteria alone. However, the importance of TNF-a for BMTT was highlighted by its support of tumor invasion and colonization in concert with lower infective doses of Salmonella. In consideration, bacterial therapeutic effectiveness along the axis of LPS and TNF-a appears limited, and does not offer the necessary plasticity for different tumors. This emphasizes a need for recombinant strengthening and vehicular exploitation to accommodate potency, plasticity and distinctiveness in BMTT.

\section{INTRODUCTION}

Tumor therapy using bacteria represents a concept with a long standing tradition [1]. Infection with various bacterial agents, alone or in combination, became an early strategy to counteract tumor growth $[2,3]$. Pioneers such as William B. Coley deployed strategies of local application and/ or heat killing of bacteria to control infection while hoping to retain the therapeutic effect. Concurrently he made an early observation of a correlation between fever induction and a positive response [4].

Nowadays, explanations for the observed phenomena are partially at hand. Pathogenicity of bacteria and their dissemination accounted for the severe side effects through activation of acute innate immune responses, including a pyrogenic effect. In accordance, the field explored and promoted bacteria with intrinsic safety [5]. The gram-negative facultative anaerobic bacterium Salmonella enterica serovar Typhimurium (S. Typhimurium) prevailed as a most exploited bacterium for bacteria mediated tumor therapy (BMTT), exhibiting intrinsic therapeutic efficacy and specificity of tumor colonization [1, 6-9]. However, its application necessitates further attenuation.

Numerous reports have validated the tumor targeting ability of attenuated Salmonella across a wide range of different tumor models [10-15]. Our understanding grants Salmonella an ability to invade solid tumors via a passive 
mechanism. A chronic infection is established of above $1 \times 10^{8}$ CFU with a specificity for tumors of above 1000:1 compared to normal murine tissue $[16,17]$. In addition, the vehicular potential of Salmonella has been exploited to specifically deliver therapeutic cargo to a great variety of tumors with an astonishing degree of success [5, 18-22]. Meanwhile, the requirement of tumor-specific colonization for an intrinsic therapeutic effect remains ambiguous.

Pathogenesis of virulent gram-negative bacteria is induced via microbial associated molecular patterns (MAMPs) activating signaling cascades via surface-bound pattern recognition receptors (PRRs). The most prominent of these is Toll like receptor 4 (TLR4) recognizing Lipopolysaccharide (LPS) located on the outer membrane of gram-negative bacteria [23]. In response to systemic application of LPS, a cytokine storm is elicited that leads to an extensive physiological reaction including the activation and mobilization of immune cells that may aid and embed a tumor therapeutic effect [24-26].

Tumor necrosis factor -alpha (TNF- $\alpha$ ) is a main cytokine induced along the LPS/ TLR4 axis, and is essential for the induction of septic shock [27]. Predominantly released by innate immune cells including macrophages, the effects of TNF- $\alpha$ are pleiotropic [28]. These include a pyrogenic effect, thus creating a hypothetical link to the observations of William B. Coley that fever is induced upon bacterial application, and most likely required for effective BMTT in humans.

A first described effect of TNF- $\alpha$ is the induction of necrosis in tumors, thus explaining its denotation $[27,29]$. This property has rendered TNF- $\alpha$ a reliable read-out in various preclinical tumor models as well as a potential therapeutic adjuvant [30-32]. However, its standalone therapeutic capacity and level of contribution in BMTT remain intriguing questions, particularly considering the detrimental effects of this pro-inflammatory cytokine.

It has long been speculated that bacterial immunogenicity or adjuvanticity accounts for the intrinsic therapeutic effect of Salmonella, albeit alternate mechanisms involving tumor colonization or direct toxicity may also contribute. In support, bacterial intrinsic therapeutic effects were shown to depend on TLR4 and myD88, thus arguing for an immune based therapeutic mechanism [33, 34]. Later studies further demonstrated that bacteria stimulate an anti-tumor immune response and induce immunological memory. In particular, $\mathrm{CD}^{+}$cytotoxic $\mathrm{T}$ cells are predominantly involved in such therapeutic effects although $\mathrm{CD}^{+} \mathrm{T}$ cells may also contribute $[35,36]$. It has been suggested that the adjuvant effect of Salmonella can be ascribed to LPS (or other MAMPs) alone and/ or its induction of TNF- $\alpha$. This greatly underpins the scrutiny to BMTT. Addressing these questions is of importance, particularly considering the efforts made to tailor the intrinsic therapeutic effect of Salmonella via alteration of their LPS structure [37-39].
In the present work, we reevaluate SL7207, an attenuated variant of Salmonella Typhimurium, of which the therapeutic properties and mechanism have been extensively characterized $[16,17,35,40]$. Using an approach of minimizing therapy, we asked the question to which extent therapeutic effects can be induced by purified LPS or recombinant TNF- $\alpha$ relative to viable SL7207. Our evaluation takes use of the colon and renal carcinoma models CT26 and RenCa, respectively. These were shown to exhibit differential susceptibility to Salmonellamediated tumor therapy [36], thus providing a framework to assess the therapeutic plasticity of minimized therapies.

\section{RESULTS}

\section{Tumor regression is inducible by $\mathrm{LPS}$}

Live bacteria underlie the majority of preclinical investigations concerning BMTT and, more recently, even clinical trials $[41,42]$. It may have generated the impression that viable bacteria are a prerequisite for efficacy in this type of therapy. In our own work, this includes investigations using viable $S$. Typhimurium SL7207 and the transplantable colon carcinoma CT26. Thus, an important question remained, namely: to which extent does LPS or the downstream effector molecule TNF- $\alpha$ constitute components responsible for an intrinsic bacterial anti-tumor effect?

In a first step we determined if SL7207 mediated therapeutic effects are titratable. If so, it could imply a direct correlation with immunogenic components like bacterial PAMPs. As expected, development of both CT26 and RenCa tumors was influenced by infection. However the therapeutic potency was dependent on the dose of infection (Figure 1A, 1B). Only an infection dose of above $1 \times 10^{6}$ caused persistent CT26 tumor regression in all replicates $\left(15 / 15\right.$ with $1 \times 10^{6}$ vs $9 / 15$ with $\left.1 \times 10^{5}\right)$, and a strong retardation of RenCa growth (2-fold decrease with $1 \times 10^{6}$ and $1 \times 10^{7}$ compared to $1 \times 10^{5}$ at $10 \mathrm{dpi}$ ). As expected, the health status of the host worsened with higher infection dose of Salmonella. Morbidity and fatal loss of body weight were consequences of an infection dose of $1 \times 10^{7}$ (Figure 1C), thus establishing a dose limitation in our model with SL7207.

As a measure of innate immune reactions, we measured the systemic TNF- $\alpha$ response with altering doses of salmonellae. The serum levels of TNF- $\alpha$ directly correlated with the infection dose of SL7207 (Figure 1D). As TNF- $\alpha$ is a known downstream mediator of bacterial PAMPs, particularly of Lipopolysaccharide (LPS), we hypothesized that LPS per se would induce similar therapeutic effects.

To determine the isolated contribution of LPS, we deployed single-dose systemic injection of purified LPS to tumor-bearing mice and evaluated the effects on CT26. 
Surprisingly, CT26 tumor development was completely abrogated. The kinetic of regression was similar to viable SL7207 (Figure 2A). To generalize effects, LPS molecules from different bacterial sources were deployed (i.e. S. typhosa and E. coli O55:B5), all of which yielded comparable results (Figure 2).

In contrast, with more resistant RenCa tumors purified LPS induced only transient growth regression using sub-lethal doses (Figure 2B, Supplementary Figure 1). This would suggest that LPS alone is inadequate to clear this type of tumor. Of note, also SL7207 caused at best only retardation in the RenCa system, highlighting that this particular type of tumor exhibits greater general resilience to BMTT.

The mere transient effect of purified LPS was reflected in the body weight profile of the murine hosts.
A weight loss of $15 \%$ on day $1-3$ post inoculation led to normalization by 5 dpi (Figure 2C). In line with current dogma explaining an endotoxic effect, application of LPS induced a TNF- $\alpha$ response. The kinetic profile peaking at $1.5 \mathrm{hpi}$ was similar to the systemic response to bacteria described before (Supplementary Figure 2) [16], and moreover titratable (Figure 2D). Altogether, the host body weight, tumor development, and the TNF- $\alpha$ response were affected similarly by titrated doses of Salmonella and purified LPS (Figures 1, 2, Supplementary Figure 1). Similarity between the therapeutic profiles would imply that bacterial therapeutic effects are indeed elicited along this axis, albeit more PAMPs and other mechanisms could contribute in the case of bacteria.

We have previously shown that SL7207 stimulates a tumor specific $\mathrm{CD}^{+} \mathrm{T}$ cell response capable of rejecting

\section{$-\begin{array}{llllll}-1 \mathrm{e} 3 & -1 \mathrm{e} 4 \quad \ldots & -1 \mathrm{e} 5 & -1 \mathrm{e} 7\end{array}$}

A

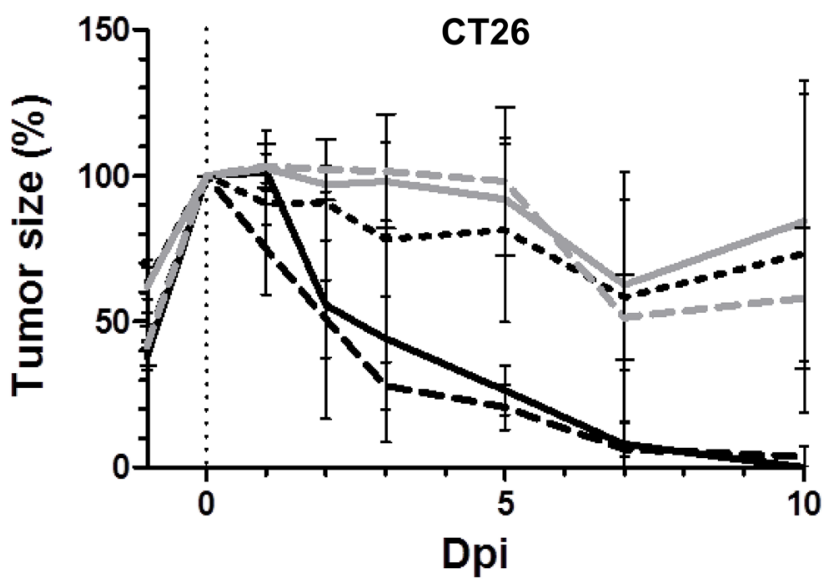

C

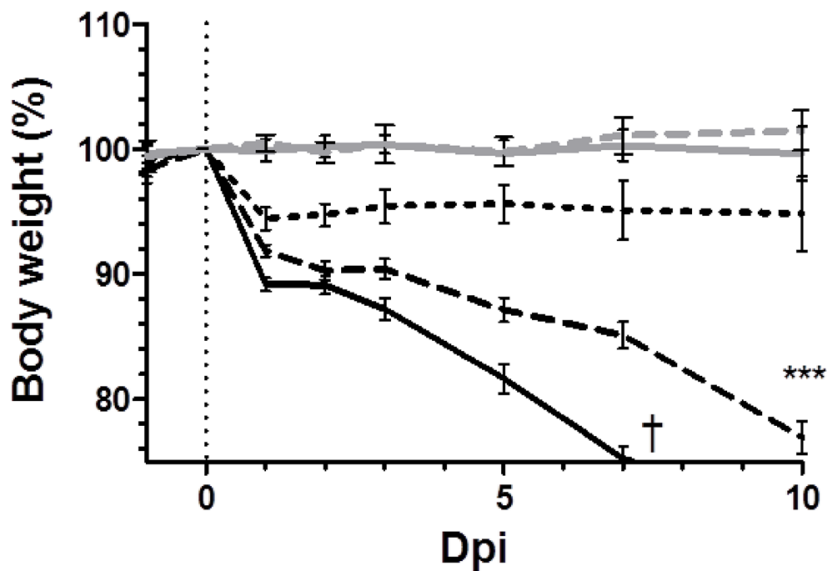

B

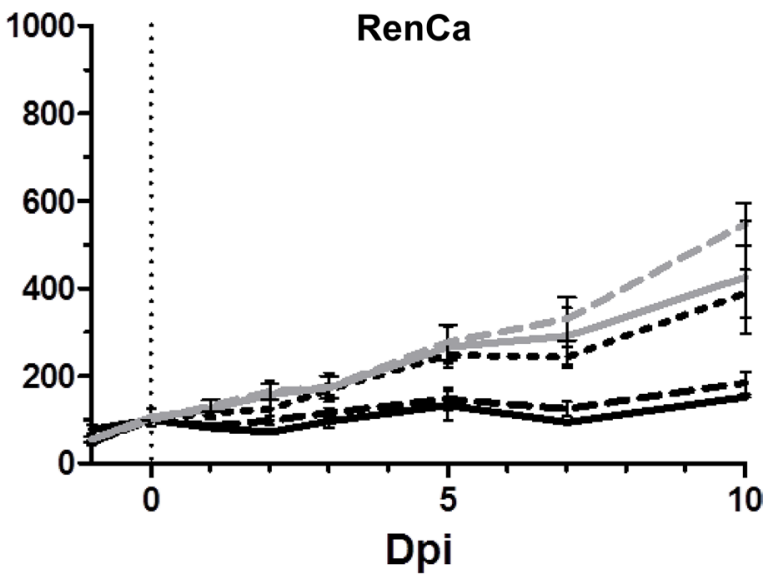

D

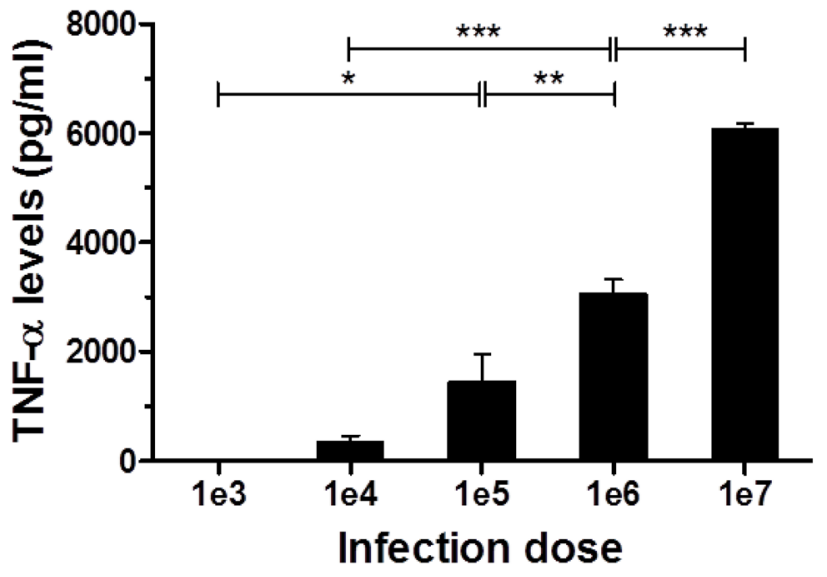

Figure 1: Dose-response relationship between SL7207 and therapeutic effects. Tumor-bearing mice were inoculated i.v. with titrated doses of viable SL7207, as indicated. (A) CT26 tumor development profiles. $N=5$. (B) RenCa tumor development profiles $N=6$. Therapeutic potency increases with higher infection dose. (C) Host body weight profiles. $N=5$. Increase in body weight loss with higher infection dose. (D) Levels of TNF- $\alpha$ in serum $1.5 \mathrm{hpi}$, as determined using ELISA. $N=5$. Levels of TNF- $\alpha$ increase with higher infection dose. Displayed are Means \pm SEM. Asterisks *, ** and *** denote significance levels of $p<0.05, p<0.01$, or $p<0.001$, resp. 
CT26 tumors [35]. Mice that recovered from CT26 upon single LPS treatment were analogously resistant to rechallenge with CT26 (Supplementary Figure 3), indicating that a tumor specific memory response had been evoked. We next asked if $\mathrm{CD}^{+} \mathrm{T}$ cells are activated via LPS treatment. To address this question, we performed a series of adoptive transfer experiments in $\operatorname{Rag} 1^{-/-}$mice using an established protocol (Figure 3A) [35, 36]. Purified LPS induced a pool of $\mathrm{CD}^{+} \mathrm{T}$ cells capable of preventing CT26 tumor establishment in Rag $1^{-/}$mice (Figure 3B). By 14 days post reconstitution with CD8+ T cells, individual tumor masses were significantly reduced below measurable and palpable sizes (Figure 3C). As seen before, the mere presence of a CT26 tumor in a mouse already stimulated a tumor specific $\mathrm{CD} 8^{+} \mathrm{T}$ cell response capable of retarding tumor growth in reconstituted $\mathrm{Rag} 1^{-/}$mice
(Figure 3B; group: “CD8 ${ }^{+} \mathrm{T}$ cells (CT26)"). However, net tumor volumes 14 days post transfer revealed that a proportion of these recipients were unable to control the outgrowth of the tumor (Figure $3 \mathrm{C}$ ). This suggests that the pre-stimulation by CT26 alone might not result in a sufficiently high number of tumor-reactive $\mathrm{CD}^{+} \mathrm{T}$ cells required to counteract the tumor in every case. Similar reconstitution experiments using $\mathrm{CD}^{+} \mathrm{T}$ cells did result in limited growth retardation under similar conditions. However, equal efficiency between different groups ("LPS", "SL7207" and "CT26") argued for an insignificant influence on $\mathrm{CD}^{+} \mathrm{T}$ cells by purified LPS alone. (Figure 3D, 3E).

Taken together, systemic LPS therapy alone is sufficient to enhance a tumor-specific $\mathrm{CD} 8^{+} \mathrm{T}$ cell response as required for CT26 tumor rejection. This highlights a

- - LPS (S. typhosa) ‥ LPS (E. coli 055:B6) - SL7207 = - CTRL

A

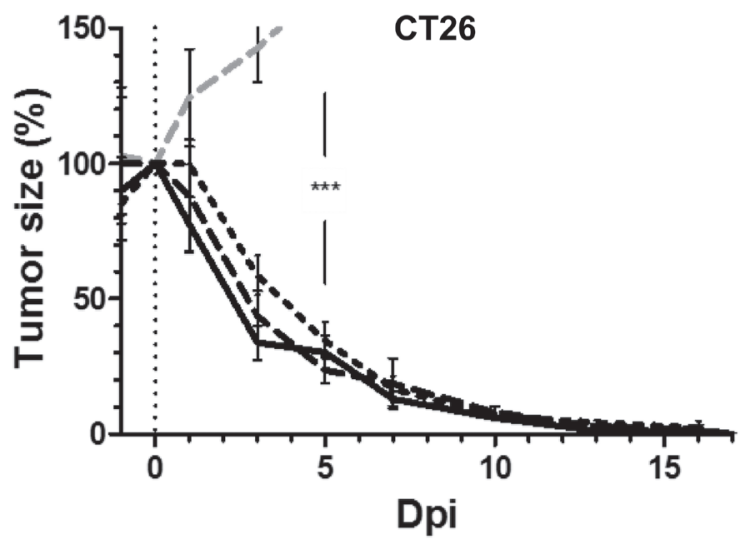

C

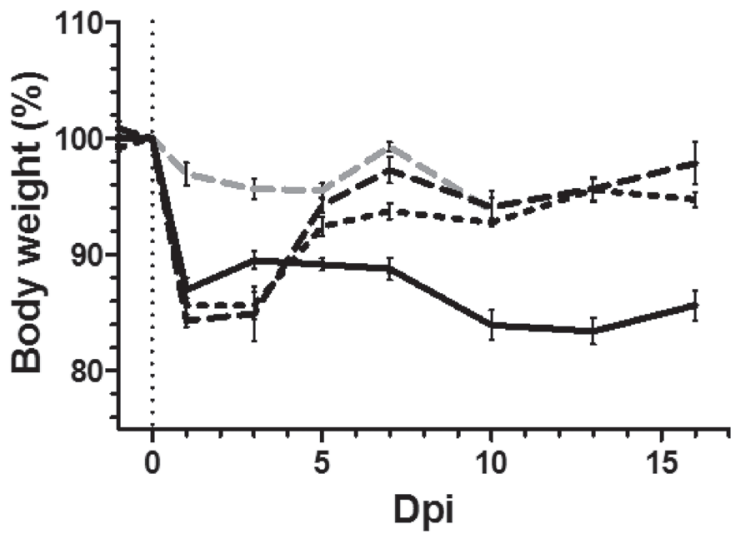

B

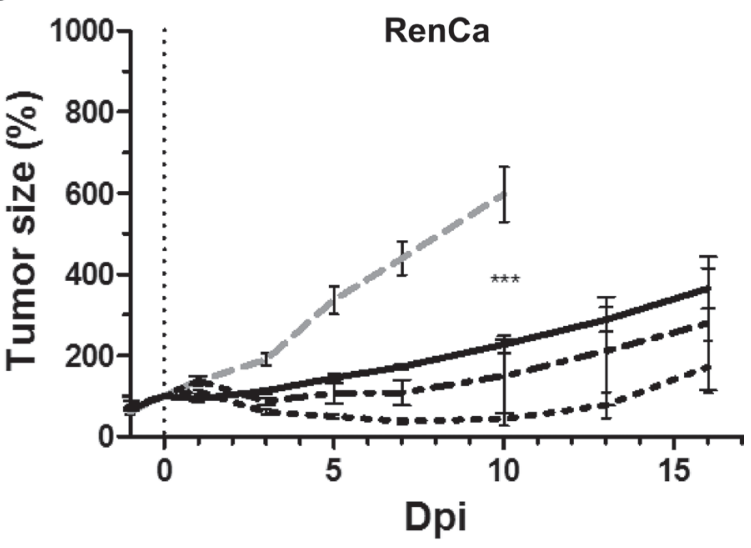

D

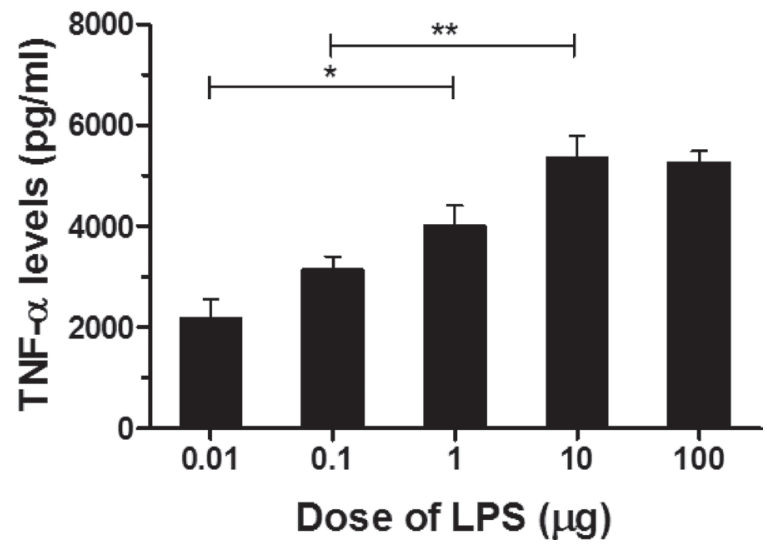

Figure 2: Single-dose purified LPS induces CT26 clearance and exhibits transient potency against RenCa. Tumorbearing mice were inoculated i.v. with $5 \times 10^{6}$ viable SL7207 or $50 \mu \mathrm{g}$ purified LPS from Salmonella typhosa or E. coli O55:B6, before comparing the therapeutic outcomes. (A) CT26 tumor development profiles. $N=5$. Treatments display a comparable kinetic of tumor regression. (B) RenCa tumor development profiles $N=6$. Transient therapeutic benefit of systemically inoculated LPS. (C) Host body weight profiles. $N=5$. Transient weight loss in response to purified LPS, distinct from progressive weight loss during salmonellosis. (D) Levels of TNF- $\alpha$ in sera at $1.5 \mathrm{hpi}$, as determined using ELISA. $N=3$. Dose-response to LPS. Displayed are Means \pm SEM. Asterisks $*$, ** and $* * *$ denote significance levels of $p<0.05, p<0.01$, or $p<0.001$, resp. 
A

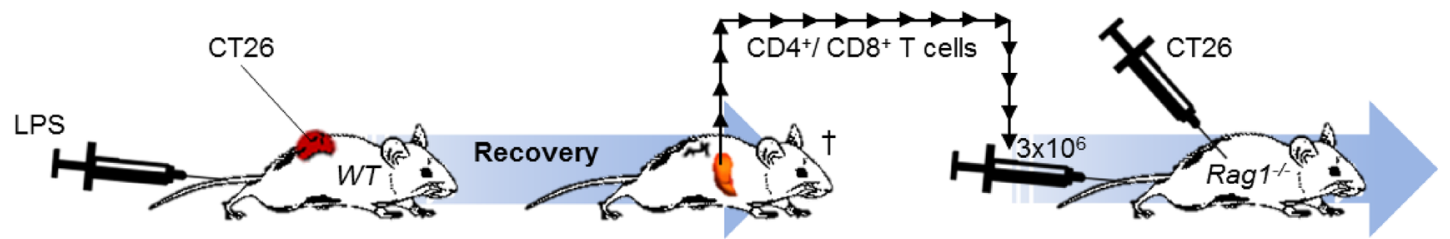

1) Successful Therapy 2) Adoptive T Cell Transfer 3) Tumor DeVelopment ?

B

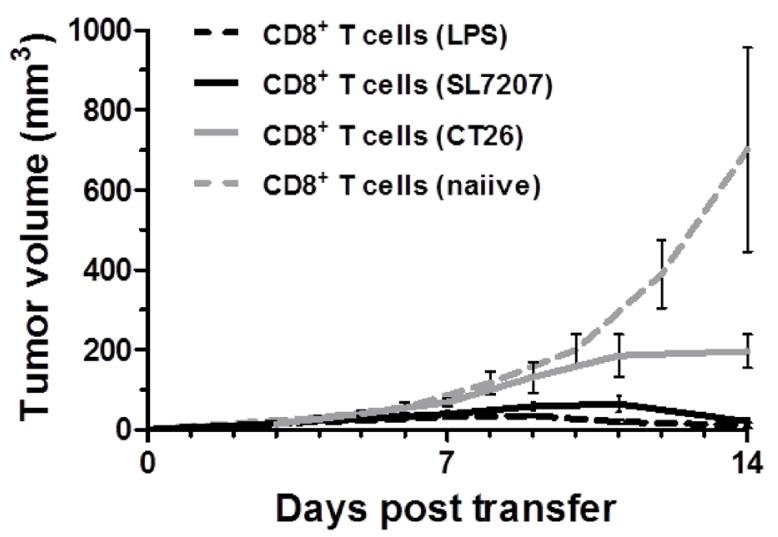

D

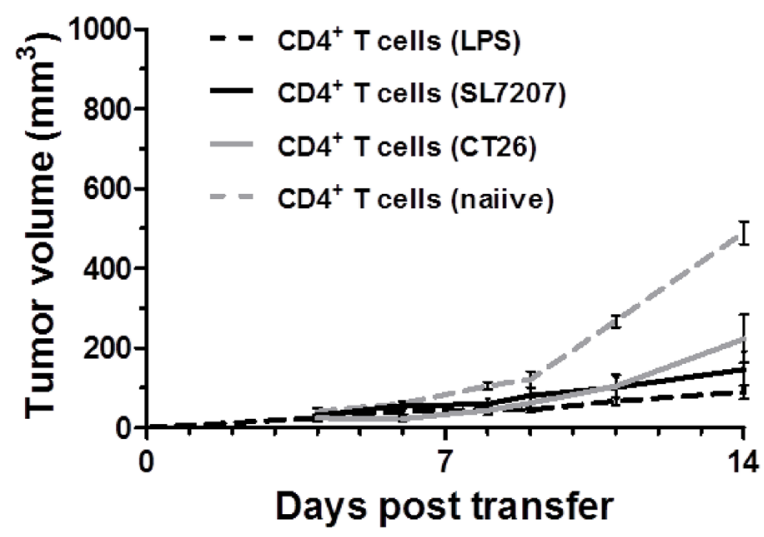

C

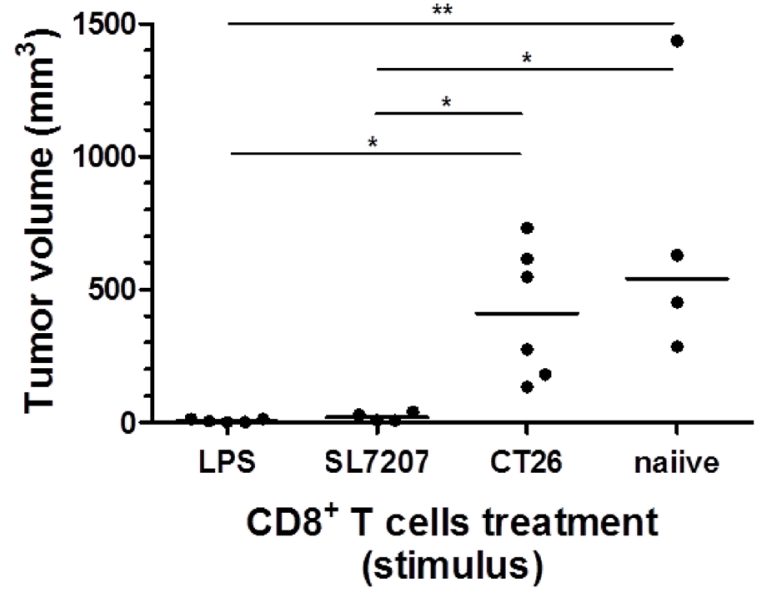

E

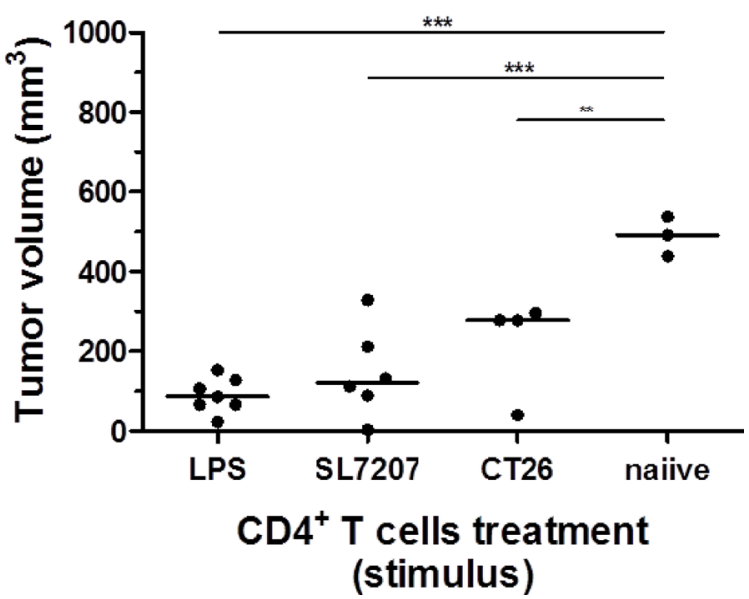

Figure 3: Analogous to SL7207, purified LPS elicits a tumor-specific $\mathrm{CD8}^{+} \mathrm{T}$ cell response capable of CT26 rejection. Therapeutic effects of pre-stimulated $\mathrm{CD} 8^{+}$or $\mathrm{CD} 4^{+} \mathrm{T}$ cell populations were evaluated on CT26 tumor growth in $\mathrm{Rag}^{-/-}$mice. (A) Schematic depiction of reconstitution experiments performed. In essence, 1) durable and complete regression of CT26 tumors through primary therapy (here purified "LPS") in wild-type mice is a prerequisite for T cell isolation. 2) Upon recovery; 3 months post therapy and antibiotic (ciprofloxacin) treatment [77], $3 \times 10^{6} \mathrm{CD}^{+}$or $\mathrm{CD}^{+} \mathrm{T}$ cells are adoptively transferred to $\mathrm{Rag} 1^{-/}$mice following negative purification from a pool of splenocytes recovered from the wild-type donor. 3) Concurrent s.c. injection of 5x10 CT26 tumor cells allows for evaluation of tumor growth and -establishment post adoptive transfer. (B) CT26 tumor development in Rag $1^{-1}$ mice reconstituted with $\mathrm{CD} 8^{+} \mathrm{T}$ cells from wild-type donors pre-stimulated as indicated in the brackets. $N=6$. (C) End-point significance comparison of mean tumor volumes in $\mathrm{Rag}^{1--}$ mice upon reconstitution with pre-stimulated $\mathrm{CD} 8^{+} \mathrm{T}$ cells. Reconstitution with LPS stimulated $\mathrm{CD} 8^{+} \mathrm{T}$ cells prevents establishment of CT26 tumors (D) CT26 tumor development in Rag1 $1^{--}$mice reconstituted with $\mathrm{CD}^{+} \mathrm{T}$ cells from wild-type donors pre-stimulated as indicated in the brackets. $N=6$. (E) End-point significance comparison of mean tumor volumes in Rag1 ${ }^{-1}$ mice upon reconstitution with pre-stimulated $\mathrm{CD}_{4}^{+} \mathrm{T}$ cells. No significant difference to the CT26 control. The (CT26)-group denotes presence of an established, albeit untreated, CT26 tumor on the T cell donor. Displayed are Means \pm SEM. Asterisks *, ** and *** denote significance levels of $p<0.05$, $p<0.01$, or $p<0.001$, resp. 
mechanistic explanation for the therapeutic activity of gram-negative bacteria like Salmonella SL7207. However, the strength of the response elicited by LPS alone only suffices to impede the growth of resistant tumors like RenCa while it remains insufficient to clear them.

\section{A TNF- $\alpha$ response underlies effective treatment of CT26}

Considering the reported role of $\mathrm{TNF}-\alpha$ and its induction via the LPS/ TLR4 axis, we asked whether this central cytokine alone may induce effects similar to LPS in the CT26 tumor model. Indeed, systemic treatment using recombinant TNF- $\alpha$ (rTNF- $\alpha)$ caused CT26 tumor regression in wild-type mice with a macroscopic developmental profile similar to previously tested more complex therapies like bacteria (SL7207) or the upstream stimulant LPS (Figure 4A). 1 dpi, darkening of the tumor tissue was evident, resulting in ulcerative necrosis over the following 3-5 days. This manifestation is symptomatic for the originally described effect of TNF- $\alpha$ and fitting with previous reports for SL7207 [16, 40]. Here, this phenotype was followed by complete tumor regression and wound healing by 3 weeks after injection.

Abrogation of the therapeutic effect in lymphopenic Rag1 $1^{-/}$mice, suggested that the therapeutic effect of rTNF- $\alpha$ depends on a functional adaptive immune system (Figure 4B) [43, 44]. This may likely be explained by an analogous adjuvant effect on $\mathrm{CD} 8^{+} \mathrm{T}$ cells as demonstrated earlier for LPS (Figure 3). In support of a memory response, also mice having cleared CT26 tumors through recombinant TNF- $\alpha$ were resistant to re-challenge with CT26 (Supplementary Figure 3). In Rag $1^{-/}$mice, rTNF- $\alpha$ displayed only a tendency of therapeutic effects at a level similar to probiotic $E$. coli, and far from the significant growth retardation observed with the more potent strain SL7207 (4 fold decrease in tumor size compared to rTNF- $\alpha$ or Symbioflor-2 at 9 dpi) (Figure 4B). Thus, B/T cell independent effects are only stimulated to a minor degree by rTNF- $\alpha$, and inferior to the effects along an anti-tumor adaptive immune response. As single-agent therapy in wild-type mice rTNF- $\alpha$ induced a substantial therapeutic effect only on CT26, and failed to yield significant therapeutic benefit with both RenCa and another highly resistant fibro-sarcoma F1.A11 (Figure 4C).

\section{Bacteria and inflammatory mediators share characteristics of solid tumor therapy}

To cast more light on the early therapeutic effects and differences in therapeutic outcomes among tumor models and treatments, we analyzed the microscopic profile of differentially treated tumors. Interestingly, CT26 tumor cross sections isolated $48 \mathrm{~h}$ post treatment with rTNF- $\alpha$ or LPS bore similar phenotypic manifestations. Control tumors were characterized by more widespread areas of hypoxia and greater dispersion of residing neutrophils and proliferative activity. All immunogenic treatments caused extensive necrosis formation towards the dorsal side of the tumor, thereby confining and localizing the neutrophils to the viable border at the remaining basal part (Figure 5A). This phenotype correlated with the macroscopic profile of tumors displayed earlier (Figure 4A). Considering the consistent manifestation of necrosis with all effective treatments against CT26, one may substantiate such as a prognostic factor in this tumor model.

Hypothesizing the same may hold true in $\mathrm{RenCa}$, we repeated our microscopic analysis with this model. RenCa generally contained more areas of hypoxia, a greater extent of proliferative activity, and less pronounced necrosis formation compared to that encountered in CT26 (Figure 5B). However, with LPS, necrosis was not as deteriorating as observed in CT26, leaving a larger viable part unaffected. This by itself could explain a reestablishment of the tumor. Neither recombinant TNF- $\alpha$ nor SL7207 displayed a marked difference compared to the control. Thus no additional clues are provided as to how SL7207 exerts its therapeutic (i.e. growth retarding) effect.

To identify the origin of the increased and localized proliferative activity, higher magnification images of the IHC staining allowed evaluating the cell morphology. While a smaller proportion of the Ki67 positive cells may constitute innate effector cells, the vast majority appeared to originate from hypertrophic tumor cells most adjacent to the necrosis (Supplementary Figure 4).

\section{Viability of Salmonella as differential requirement for successful therapy of CT26 and RenCa tumors}

The minimization of stimulants for tumor therapy proved only successful for CT26 which is evidently prone to this type of immune therapy. We therefore increased the complexity of the stimulant and investigated the therapeutic effect of heat-inactivated $S$. Typhimurium SL7207 on tumor development. Heat-inactivated Salmonella would still bear most of the stimulating molecules [45]. As expected, avitalized SL7207 induced CT26 tumor clearance with a kinetic of regression similar to viable SL7207 (Figure 6A). Endpoint tumor volumes were indifferent among the groups, reaching mean tumor sizes of $<10 \mathrm{~mm}^{3}$ by $11 \mathrm{dpi}$ and non-palpable tumors by $17 \mathrm{dpi}$ (Figure 6B). These results were corroborated with an independent bacterial agent, the $E$. coli probiotic Symbioflor-2, also displaying comparable tumor retardation profiles between viable and avitalized bacterial treatment (Supplementary Figure 5). Inability to reestablish CT26 tumors upon re-challenge after successful therapy with HI SL7207 (Supplementary Figure 3), 
supports that immune memory is likely to be elicited along the same axis as viable bacteria, purified LPS or rTNF- $\alpha$. The positive therapeutic outcome on CT26 tumors by avitalized bacteria again correlated with the histological manifestation of necrosis, analogous to treatments with both viable bacteria and LPS (Supplementary Figure 6).

To validate our results and determine if viability may just as easily be surpassed in other tumor models, we tested RenCa. In addition to heat-inactivation we included avitalization by UV irradiation. Surprisingly, and regardless the mode of avitalization, both heatinactivation and UV irradiation completely abrogated the therapeutic activity of SL7207 against RenCa tumors (Figure 6C). Endpoint tumor volumes showed no significant difference between treatments with avitalized SL7207 and PBS (Figure 6D). As expected, no presence of avitalized bacteria could be detected in the tumor upon control plating (Figure 6E), thus dissociating the

A Days post injection

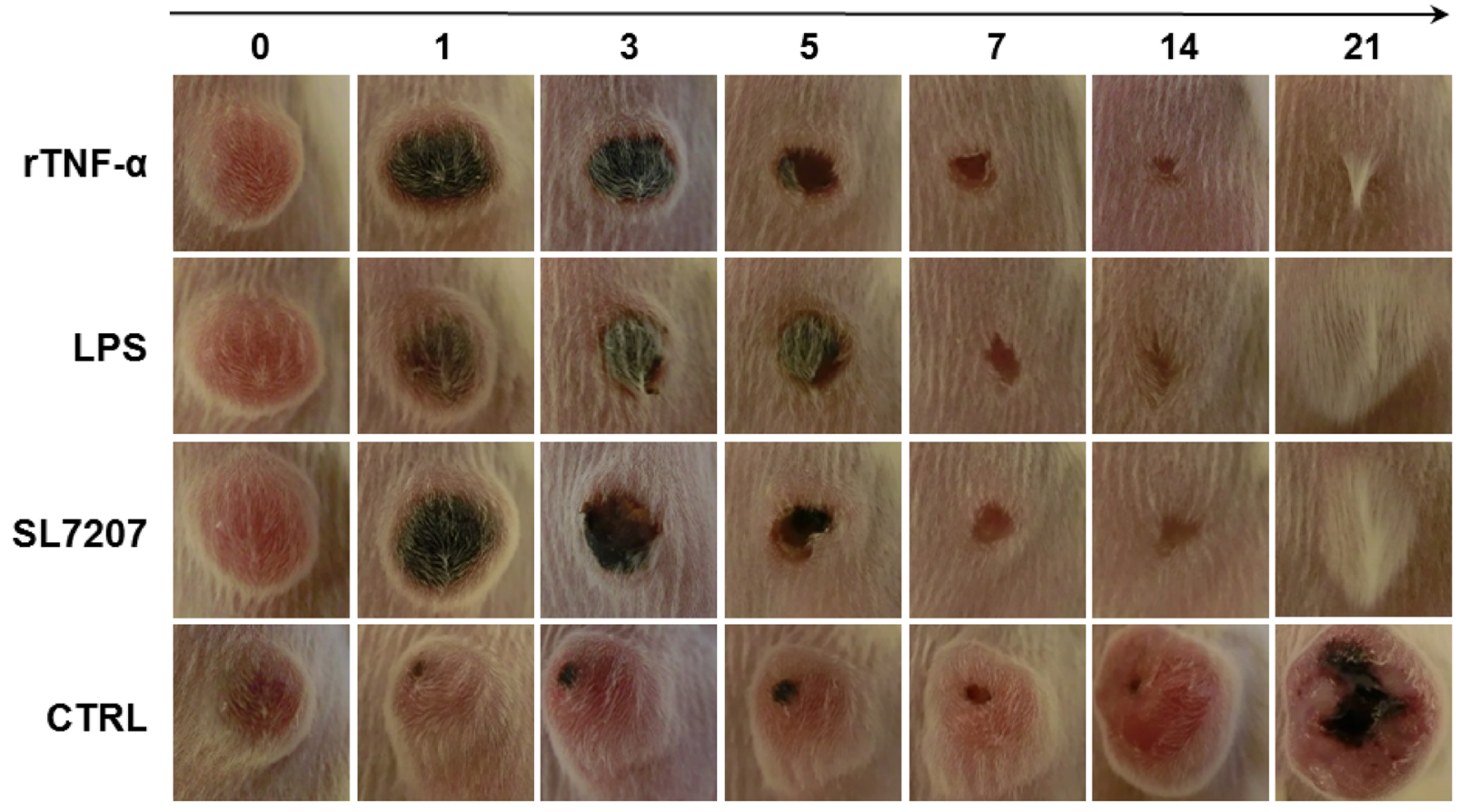

B

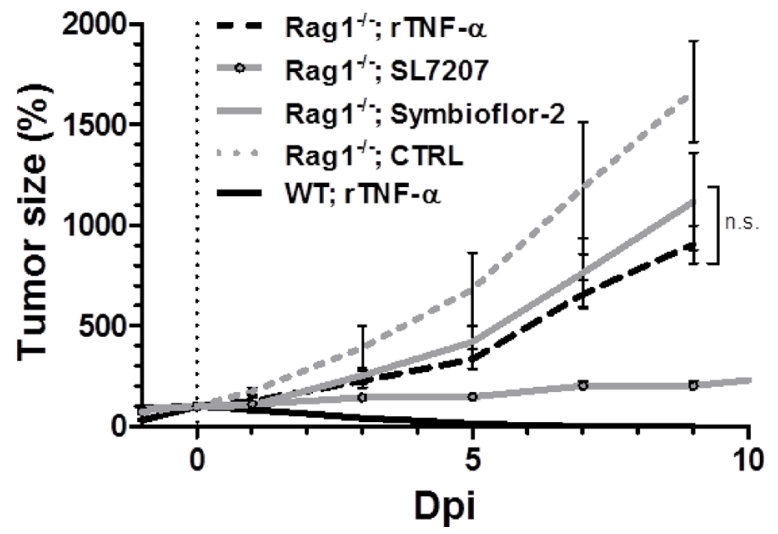

C

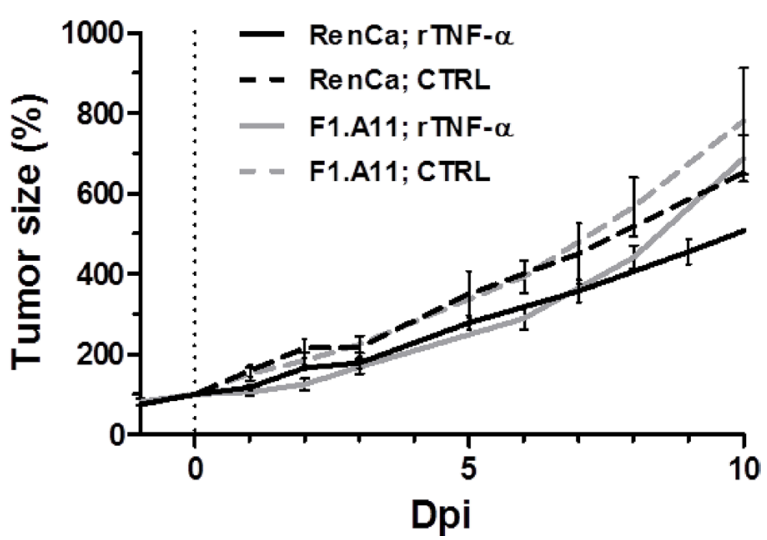

Figure 4: While exclusive to CT26, tumor clearance is equally attainable through recombinant TNF- $\alpha$ as with LPS or Salmonella, and dependent on adaptive immunity. $1 \mu \mathrm{g}$ recombinant murine TNF- $\alpha(\mathrm{rTNF}-\alpha)$ was administered i.v. and therapeutic effects in wild-type and $\mathrm{Rag}^{-/}$mice were evaluated relative to LPS therapy or BMTT. (A) CT26 tumor development in WT mice represented by close-up photographs of CT26 tumors subjected to treatments as indicated. Similar macroscopic profile of tumor darkening, ulceration and clearance between all therapies. Images displayed are representative of three individual replicates (B) Kinetic of CT26 tumor development in $\operatorname{Rag} 1^{--}$mice. $N=5$. Tumor regression with all therapies is abrogated in absence of a functional adaptive immune system. (C) RenCa and F1.A11 tumor development profiles in WT mice. $N=5$. No significant therapeutic effects induced by rTNF- $\alpha$. Displayed are Means \pm SEM. 
bacterial therapeutic effects observed on CT26 from bacterial persistence or presence in the tumor. However, lack thereof may still contain possible explanations for inefficiency against RenCa.

Evaluating the body weight over the course of treatment, avitalization altogether abrogated the detrimental effect of viable bacteria on the host. Compared to the therapy with SL7207, which induced a progressive drop in body weight by $11 \mathrm{dpi}$, mice treated with heatinactivated or UV irradiated SL7207 retained an inclining body weight profile after a transient drop of $<10 \%$ by 2 dpi (Figure 6F). This result correlated with the phenotypic appearance of the animals. In line with earlier reports [36], mice subjected to viable infection displayed fatigue and a disrupted fur coat. This was in great contrast to those subjects inoculated with heat-inactivated SL7207 and not displaying any signs of behavioral or phenotypic change (Supplementary Figure 7).

Expecting that a systemic immune reaction might be similarly induced by heat-inactivated SL7207 and may underlie the therapeutic effect on CT26, we determined the amount of TNF- $\alpha$ in serum shortly after inoculation. A systemic TNF- $\alpha$ response was indeed detected early post inoculation $(1.5 \mathrm{hpi})$. No significant difference to infection by viable bacteria was observed (Figure 6G). This indicates that also heat-inactivated SL7207 induces

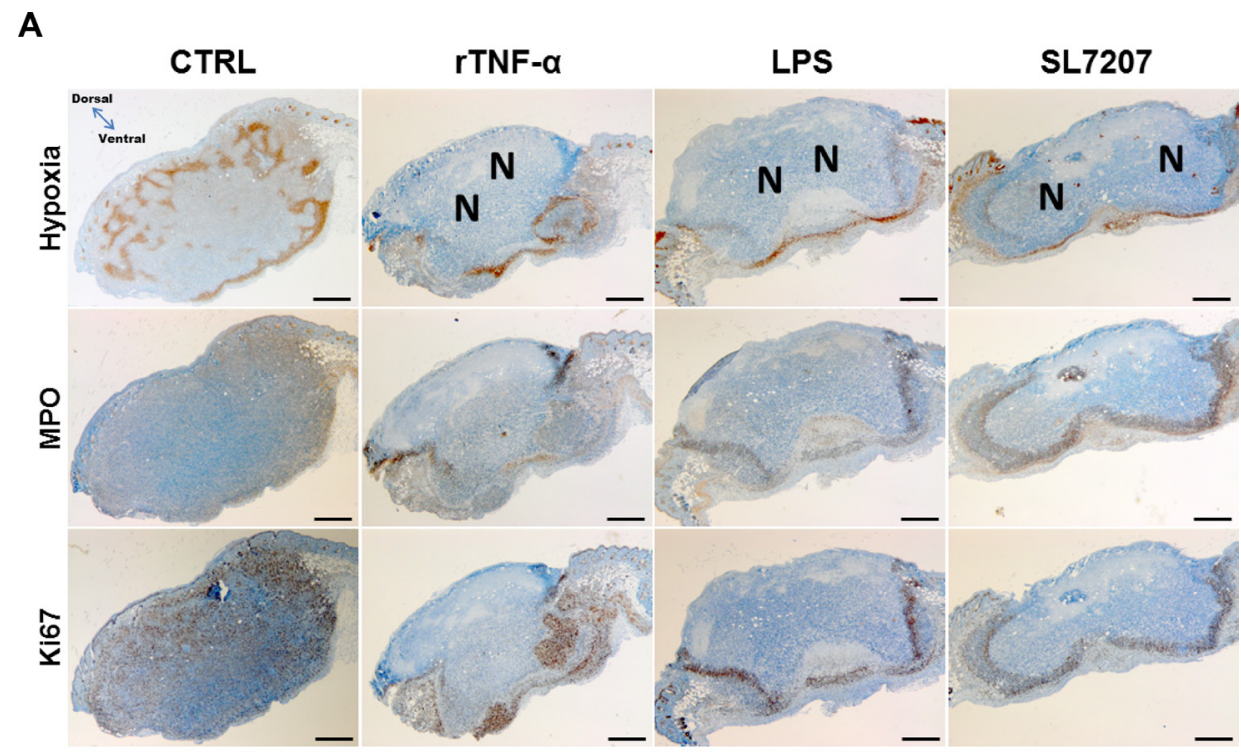

B

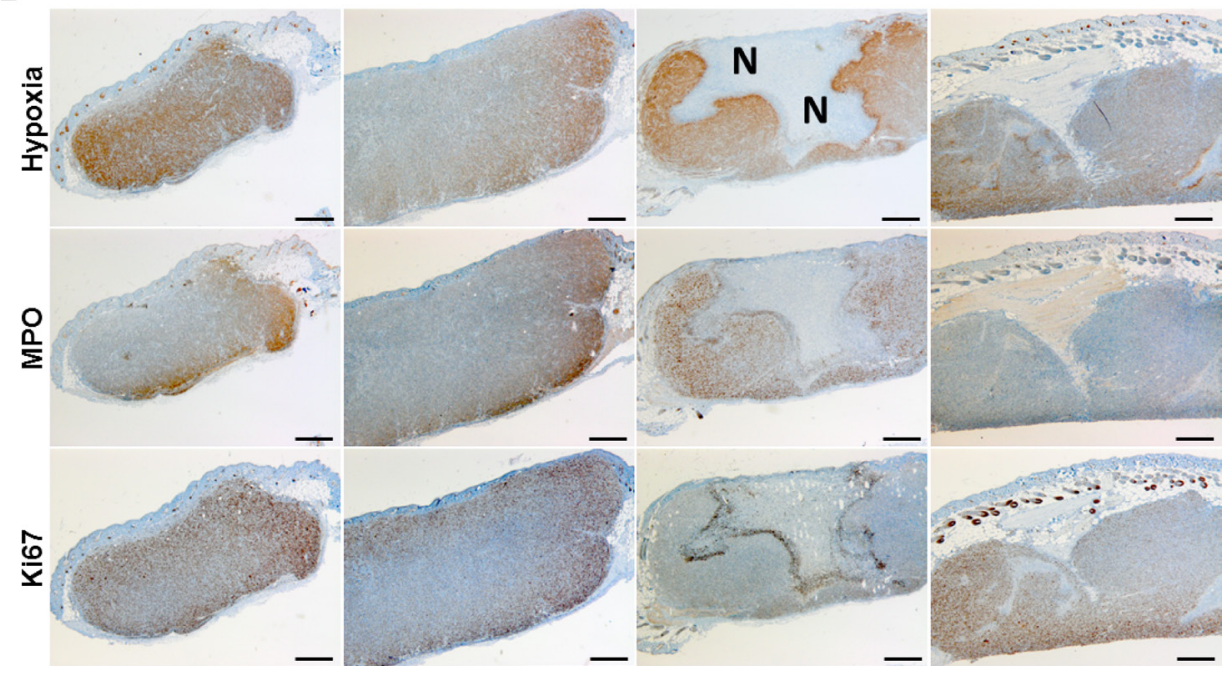

Figure 5: Prognostic characteristics of the CT26 tumor are shared among different immunogenic treatments, and less pronounced in RenCa. Tumors from treated or untreated mice were isolated $48 \mathrm{hpi}$, and subjected to immune histochemical staining. Histological images of stained CT26 (A) or RenCa (B) tumor cross sections. More extensive necrosis formation with treatments of CT26 compared to RenCa. Images displayed are representative of four replicates. "N" indicates greater areas of necrosis. Hypoxia was stained with antibodies against metabolites of pimonidazole- $\mathrm{HCl}$, otherwise administered i.v. 30 mins prior to isolation. Myeloperoxidase (MPO) denotes presence of neutrophilic granulocytes, and Ki67 the extent of proliferative activity. Differential staining was performed on consecutive sections. Scale bar corresponds to $100 \mu \mathrm{m}$. Orientation of the tumor cross section as indicated. 
a substantial cytokine response that is already sufficient for CT26 clearance.

\section{Limited efficiency of recombinant TNF- $\alpha$ in solid tumor therapy}

Although limited, TNF- $\alpha$ exhibited a certain therapeutic potential. We wondered if i) increasing TNF- $\alpha$ could be a mean to boost a therapeutic effect, and if ii) a synergistic effect would be elicited when bacteria and TNF- $\alpha$ are administered in combination. Utilizing the known differential therapeutic efficiencies of SL7207 and probiotic E. coli (Symbioflor-2) [36], we asked if recombinant $\mathrm{TNF}-\alpha$ may boost BMTT in more rigid tumor models. Co-administration facilitated a substantial increase in the systemic level of TNF- $\alpha$ at $1.5 \mathrm{hpi}$, past the response to bacteria or inoculum of rTNF- $\alpha$ alone, suggestive of positive feedback (Figure 7A). However,
A

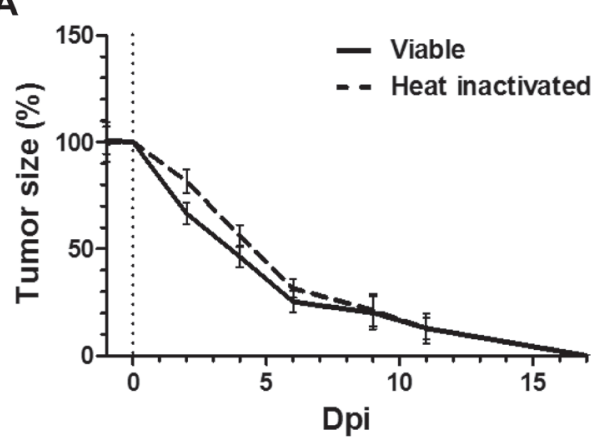

C

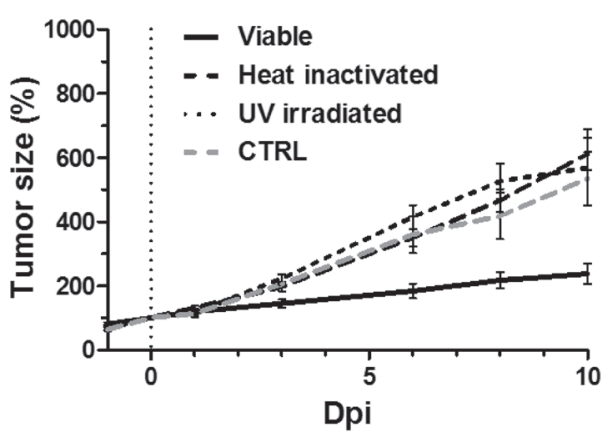

B

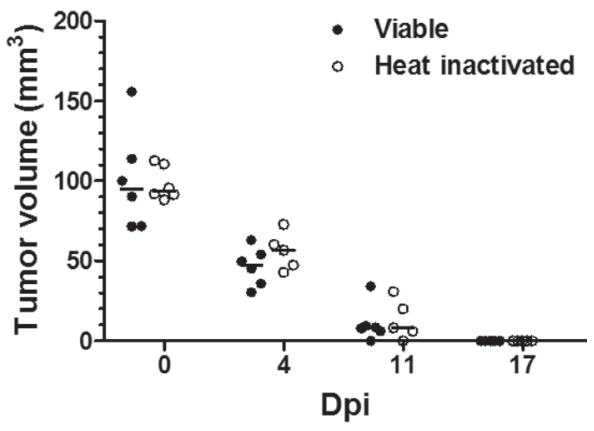

D

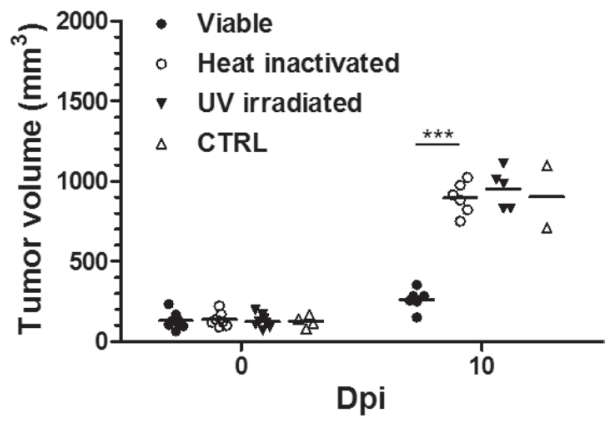

G

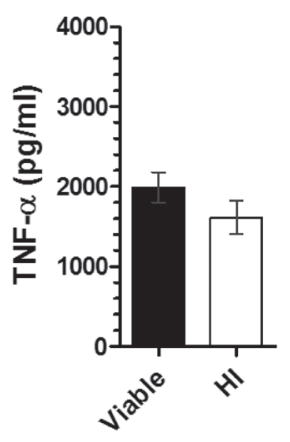

Figure 6: While dispensable for CT26 regression, viability of SL7207 is cause of an infectious phenotype, and required for the therapeutic efficacy against RenCa. Tumor-bearing mice were inoculated i.v. with $5 \times 10^{6}$ viable or avitalized Salmonella SL7207, and the therapeutic effects compared. Avitalization was facilitated through heat inactivation (HI) at $60^{\circ} \mathrm{C}$ or UV irradiation. (A) CT26 tumor development profiles. $N=6$. Mean \pm SEM. Similar kinetic of regression post treatment using viable and avitalized SL7207. (B) Statistical comparison between mean tumor volumes. No difference at indicated time points. (C) RenCa tumor development profiles. $N=6$. Mean \pm SEM. In contrast to viable SL7207, avitalization abrogates the retarding effect and causes outgrowth. (D) End-point comparison of mean RenCa tumor volumes. No significant difference between UV irradiated and HI groups. (E) CFU counts in RenCa tumors upon 48 hours of treatment, as indicated. $N=3$. Median \pm range. Only viable therapy facilitates tumor colonization (i.e. persistence) of SL7207 in the host. (F) Host body weight profile dictated by recovery for avitalized groups, and progressive loss with viable SL7207. $N=6$. Mean \pm SEM. (G) Levels of TNF- $\alpha$ in sera at $1.5 \mathrm{hpi}$, as determined using ELISA. $N=5$. Mean \pm SEM. No significant difference between viable and avitalized treatments. Asterisks $* * *$ and $* * *$ denote significance levels of $p<0.05, p<0.01$, or $p<0.001$, resp. 
combination therapy of rTNF- $\alpha$ and Symbioflor-2 did not influence the RenCa tumor development relative to Symbioflor-2 alone, and also the tumor retarding effect of SL7207 did not improve in combination with rTNF- $\alpha$ (Figure 7B). These results were corroborated using a different tumor model F1.A11 with a similar outcome (Figure 7C). Endpoint tumor volumes did not display significant differences in either model upon co-injection of TNF- $\alpha$ (Figure 7D, 7E). Moreover, these results were transferrable to $\operatorname{Rag}^{-/-}$mice (data not shown).

Taken together, these results suggest that effector mechanisms induced by TNF- $\alpha$ at the therapeutic phase of BMTT may already be driven to its limit by the bacteria alone and that no additional effect can be achieved when recombinant TNF- $\alpha$ is applied in combination with the bacteria.

\section{Exogenous TNF- $\alpha$ supports tumor invasion under limiting conditions}

As demonstrated in our experiments using recombinant $\mathrm{TNF}-\alpha$, this cytokine supports the clearance of solid tumors to a certain extent. During the phase of bacterial invasion into the tumor its vascular disrupting activities might be essential, and are most likely responsible for the early retardation of tumor growth $[16,31,46]$. In consideration, we tested the effects of exogenous TNF- $\alpha$ under conditions where the spontaneous induction of this cytokine is minimized. To this end, we reduced the number of bacteria in the inoculum. Supporting a dose-dependent relationship, serum levels of active TNF- $\alpha$ were reduced below detection limit early after infection with a 100-fold lesser inoculum of $5 \times 10^{4} \mathrm{CFU}$ (Figure 8A). However, an exogenous supply of rTNF- $\alpha$ installed comparable systemic levels, thereby hypothetically allowing for therapeutically beneficial activities compensatory to those of endogenously induced TNF- $\alpha$. Using this setup, we determined the ability of Salmonella bacteria to invade CT26 tumors under minimized conditions. Compared to the standard inoculum of $5 \times 10^{6}$, lower doses of $5 \times 10^{4}$ and $5 \times$ $10^{3}$ resulted in colonization of only $63 \%$ and $22 \%$ of all CT26 tumors, respectively (Figure $8 \mathrm{~B}$ ). Additionally, the level of colonization per tumor at $48 \mathrm{hpi}$ was decreased in a dose-dependent manner, resulting in more than a 10 -fold reduction in tumor CFU with an infection dose of $5 \times 10^{4}$ (Figure 8C). Surprisingly, the addition of exogenous rTNF- $\alpha$ reinstalled the colonization efficiency
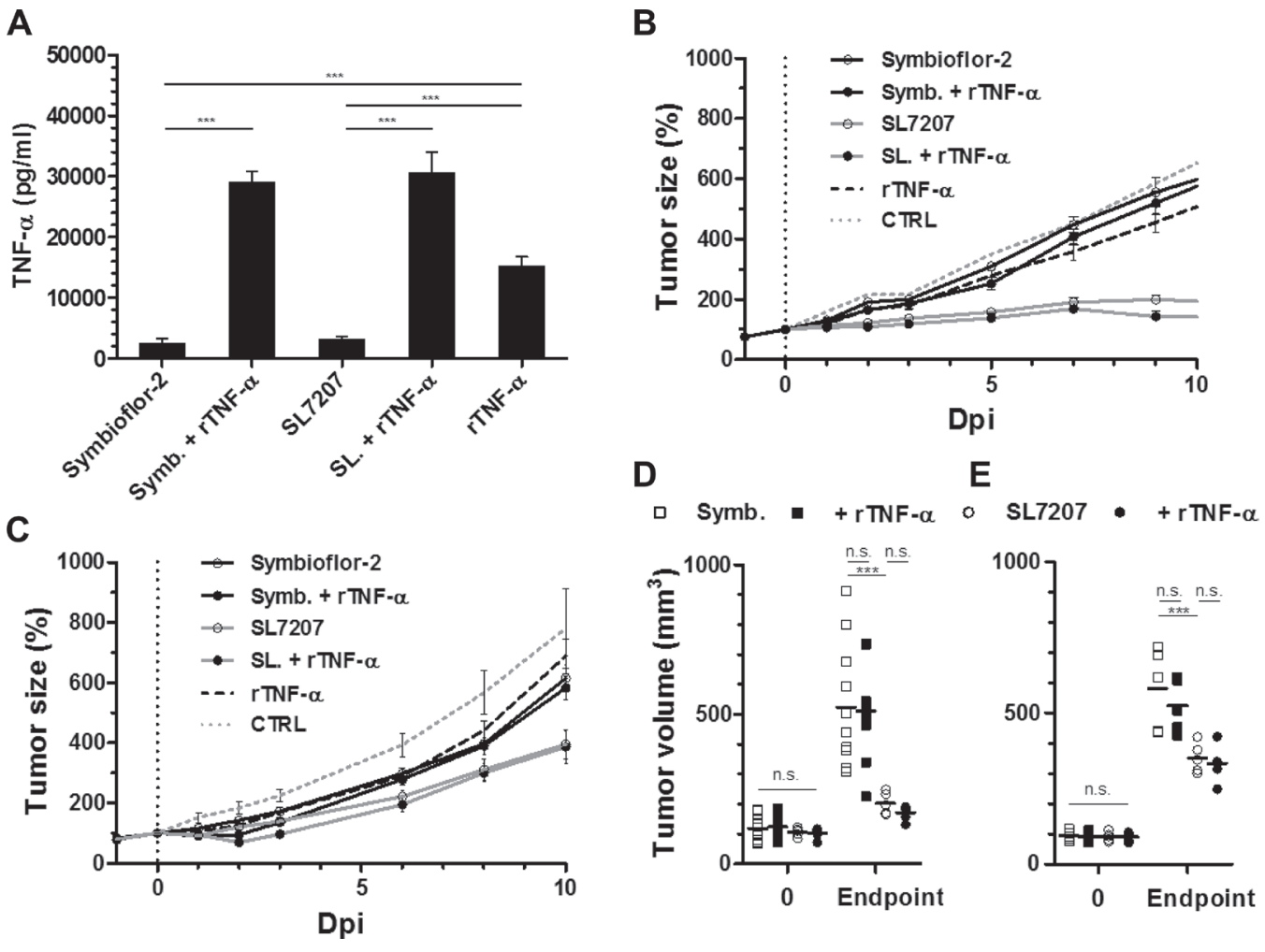

Figure 7: Co-injection of recombinant TNF- $\alpha$ does not improve bacterial anti-tumor effects in more rigid tumor models. Tumor-bearing mice were inoculated i.v. with $5 \times 10^{6}$ Salmonella SL7207 or E. coli probiotic Symbioflor- 2 in concert with $1 \mu \mathrm{g}$ recombinant TNF- $\alpha$. Therapeutic efficacies were compared. (A) Levels of TNF- $\alpha$ in sera at 1.5 hour post treatment, as determined using ELISA. $N=5$. Combination therapy yields excessive levels of TNF- $\alpha$. (B) RenCa tumor development profiles in treated WT mice. $N=8$. (C) F1.A11 tumor development in treated WT mice. $N=5$. (D) Endpoint RenCa tumor volume. Comparison at 9 dpi. (E) Endpoint F1.A11 tumor volume. Comparison at $10 \mathrm{dpi}$. TNF- $\alpha$ supplementation does not improve bacterial therapeutic effects. Displayed are Means $\pm \mathrm{SEM}$. Asterisks *,** and $* * *$ denote significance levels of $p<0.05, p<0.01$, or $p<0.001$, resp. 
and partially improved the colonization frequency (Figure 8B, 8C). Interestingly, while adverse colonization of spleen was reduced with lower infection doses no marked change was observed upon supply of rTNF- $\alpha$ (Figure 8D).

As exogenous rTNF- $\alpha$ was able to partially rescue the therapeutic activity of bacterial tumor invasion, the importance of this cytokine could be illustrated in that, it needs to be induced to a certain concentration for BMTT to become effective.

\section{DISCUSSION}

This study aimed to determine if tumor-therapeutic effects against CT26 and RenCa described for SL7207 can be equally induced via avitalized bacteria, LPS or recombinant TNF- $\alpha$, likely accounting for the dominant adjuvant pathway of gram-negative bacteria. Moreover, we intended to define limits of these adjuvant effects. We found that regression of CT26 tumors can be equally accomplished via single application therapy using recombinant TNF- $\alpha$ or purified LPS. It resulted in the induction of an effective anti-tumor $\mathrm{CD} 8^{+} \mathrm{T}$ cell response. In contrast, therapeutic effects against RenCa were abrogated upon avitalization of SL7207, only transiently present using high-dose purified LPS, and altogether absent using excessive amounts of rTNF- $\alpha$. This demonstrates a requirement of viability and persistence of bacteria for therapeutic efficacy against RenCa tumors. Co-injection of rTNF- $\alpha$ with E. coli probiotic Symbioflor-2 or SL7207 did not improve bacterial therapeutic effects thereby suggesting that adjuvant effects are exhausted already by the bacteria alone under these conditions. However, the ability of rTNF- $\alpha$ to rescue the efficiency of tumor colonization with lower infection doses emphasizes the importance of this cytokine for tumor invasion.

Our study explored the often stated hypothesis that BMTT using gram-negative bacteria can be reduced to a mere adjuvant effect stimulating an anti-tumor immune response exclusively along the LPS/ TLR4 axis. While this mechanistic pathway was shown to apply in some cases, our study clearly demonstrates that sufficiency of such an intrinsic effect is tumor model dependent. In addition $\mathrm{B} / \mathrm{T}$ cell independent effects in Rag $1^{-/-}$mice could be observed with therapy using viable SL7207.

The ease of CT26 clearance via single-shot therapy using LPS and rTNF- $\alpha$, and thus stimulation of a preexisting CT26-specific CTL response, would suggest an easily over-turnable immune status for this type of tumor [47]. Thus, CT26 is rendered highly susceptible to this type of immunotherapy. Similar macroscopic profiles and an identical kinetic of regression of CT26 obtained with all types of therapeutic stimulants support this notion. Alternatively, more resistant models, like RenCa, may more appropriately reflect the clinical challenge and allow to asses bacterial therapeutic effects more accurately [10, 48-50].

The explanation of this differential susceptibility to adjuvant therapy between CT26 and RenCa remains uncertain. As innate immune responses (i.e. TNF- $\alpha$ ) to SL7207 or E. coli remained comparable between CT26 and RenCa (Supplementary Figure 8), one would not speculate a difference in such between CT26 and RenCa. Hence, it may be the extent of resistance or escape mechanisms e.g. immune editing or check-point inhibition versus immune recognition and availability of tumor antigen. Other explanations may be given by the tumor architecture e.g. vascularization and accessibility for immune cells. Our histological analyses suggested necrosis formation may be a prognostic factor for clearance of CT26 tumors, supporting current dogma $[40,51]$. It showed that indeed this feature is attainable by minimized therapy using LPS or rTNF- $\alpha$. However considering also the requirement of an adaptive immune response, one may speculate that the extent of necrosis formation in the induction phase is crucial to reduce the tumor mass to a level where the capacity of the immune system is able to outbalance the remaining tumor growth. The more prudent manifestation of necrosis in RenCa would support this theory, although complete absence with SL7207 argues for a different explanation or mechanism in case of bacteria. Here, the outgrowth in spite of retardation would suggest that the capacity of the anti-tumor immune response is exceeded. While successful clearance of RenCa may surely require supplementation in an extrinsic form [1, 5, 52, 53], the localized constant stimulation by persistent Salmonella sets it apart from single agent immune therapies externally delivered to the tumor.

A differential viability requirement was shown for CT26 and RenCa. Our results demonstrate that bacterial viability or persistence, hence tumor colonization, is expendable for the adjuvant effect. This raises several questions. i) At which location does the stimulation of tumor reactive $\mathrm{T}$ cells take place if not in the colonized tumor, and ii) do reactions against bacterial antigens and/ or tumor colonization add substantial benefit to a viable bacterial therapy. The latter may explain the difference with RenCa. To which extent bacterial tissue destruction, liberation of neo-antigen, local stimulation of immune cells and a persistent stimulus are important or represent mechanisms that substantially contribute a therapeutic effect remains to be demonstrated.

The frequent attention on neutrophils in relation to bacterial immune therapy may have generated the impression of such as an important mediator of a therapeutic effect $[54,55]$. Analogously, the neutrophil containment of bacteria was brought forth by our research group as an important mechanism of control, and potential therapeutic aid via modulated and polarized activities $[40,56-58]$. However, the presence of a neutrophil barrier 
around the induced necrosis was equally attainable by rTNF- $\alpha$ or LPS. While this may disprove a requirement of bacterial colonization for immigration of innate immune cells to the tumor, the impact of bacteria on the functionality of these and other innate effector cells, including macrophages and NK cells [59], remains ambiguous.

In accordance with current dogma, LPS was shown to be a potent MAMP of gram-negative Salmonella, and TNF- $\alpha$ a downstream cytokine alone capable of inducing tumor necrosis and reinforcing a specific adaptive immune response. Not surprising, these stimulants are in focus as potential therapeutic adjuvants or as molecular targets for immune modulation in BMTT [30, 60-62]. However, one should keep in mind their naturally detrimental effect. Compromised safety may prohibit the option of boosting effects by higher dosing or re-stimulation, thus limiting application regimens. Along this line, sub-lethal doses of LPS at best caused only a transient therapeutic effect in our study, in spite of inducing excessive amounts of TNF- $\alpha$. This suggests that such a mechanistic axis has a limited therapeutic effect. What may certainly challenge the feasibility of application is the consideration that humans, in downstream therapeutic application, would not exhibit the high tolerance to systemic LPS as murine subjects [63]. Generally, therapy along this axis alone may not represent a therapeutic strategy dictated by sustainability and plasticity for different types of tumors.

Comparison between therapeutic effects of purified LPS and bacteria was drawn from inoculi standardized according to maximal tolerated doses. Sub-lethal doses of $50 \mu \mathrm{g}$ purified LPS and $5 \times 10^{6}$ salmonellae were applied, both of which caused significant systemic TNF- $\alpha$ responses, $100 \%$ CT26 regression, and retardation of
A

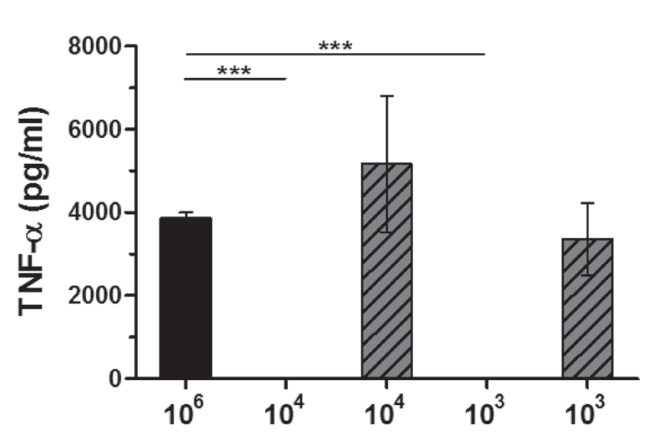

C

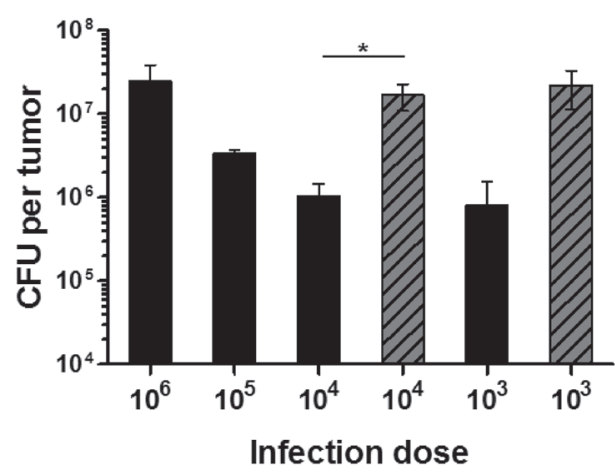

B

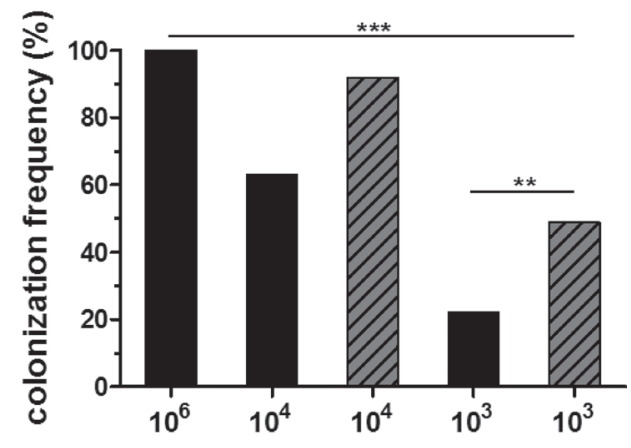

D

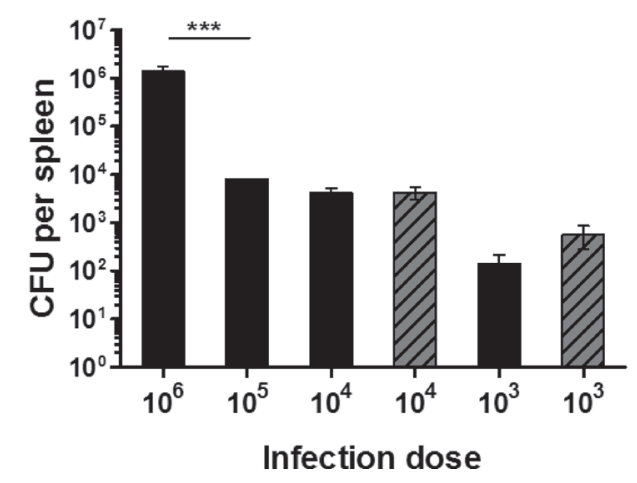

Figure 8: While the infectious dose of Salmonella decides about effectiveness of colonization, TNF- $\alpha$ supplementation supports tumor invasion at lower inoculi. CT26 tumor-bearing mice were inoculated i.v. with Salmonella SL7207 alone or in combination with $1 \mu \mathrm{g}$ recombinant TNF- $\alpha$. Infectious doses were titrated from $5 \times 10^{6}$, decreasing in increments of 1 log down to $5 \times 10^{3}$. (A) Level of active TNF- $\alpha$ in sera as determined using a TNF- $\alpha$ sensitive C5F6 fibroblast bioassay. $N=5$. Mean \pm SEM. Lower doses fail to induce a significant TNF- $\alpha$ response. Exogenous rTNF- $\alpha$ can yield compensatory levels. (B) Frequency of colonized CT26 tumors. Results were pooled from three separate experiments. (C) CT26 tumor colonization 48 hpi. Tumors not colonized (refer to Figure 8B) were excluded from this calculation. Displayed are Medians \pm range. Lower doses substantially reduce the frequency and efficiency of tumor colonization, compensable through co-injection of rTNF- $\alpha$. (D) Splenic colonization. $N=5$. Median \pm range. Gradual decrease in adverse colonization with lower infectious doses and no marked change upon supply of rTNF- $\alpha$. Asterisks *,** and *** denote significance levels of $p<0.05, p<0.01$, or $p<0.001$, resp. 
RenCa tumor growth. Based on stoichiometric calculations considering between 2-50 fg LPS per cell [64-66], $5 \times 10^{6}$ salmonellae would retain between 10-250 ng bacterial derived LPS. By this estimation, Salmonella exerted therapeutic effects at a much lower concentration of LPS. However, in viable Salmonella, LPS represents only one of many immunogenic components including PAMPs which contribute to a therapeutic effect, and are constitutively supplied in concert with turnover and colonization. Signal transduction may differ depending on different immunogenic profiles, and hence also the therapeutic phenotype concerning innate cytokine and effector responses may differ between bacteria and purified LPS [39, 67, 68]. Deriving conclusions from a comparison may be further complicated by a difference in in vivo stability and biochemistry of different supply routes of LPS, considering as example micelle formation and aggregation of purified LPS. Nevertheless, principles demonstrated for LPS may be translated to more complex bacteria, if not directly compared in terms of stoichiometry.

At no point did TNF- $\alpha$ alone or as supplement exceed the therapeutic effects of bacteria alone. In accordance, neither SL7207 nor the less potent Symbioflor-2 [36] gained advantage by supplementation of TNF- $\alpha$. This suggests that TNF- $\alpha$ induction by bacteria already retains the maximum therapeutic effect along this particular axis. While indisputably the most dominating cytokine induced by infection in this model system, a diversity of additional expressed and modulating cytokines like IL-6, IL-12, MCP-1, IFN- $\beta$, IFN- $\gamma$ and IL-10 may also contribute to the therapeutic outcome with bacteria $[16,69]$.

The inefficiency of rTNF- $\alpha$ against RenCa compared to SL7207 would imply that bacterial therapeutic effects observed are elicited along a different pathway in this tumor model. Dependence on viability would also suggest that these therapeutic effects are ascribed to other than the immunogenicity of the bacterium alone. This would have been vastly preserved with the avitalization procedures. Explanations may still include local induction of TNF- $\alpha$ in the tumor or induction of alternate cytokines that may add therapeutic effects. More direct therapeutic effects may be ascribed to SL7207 tumor colonization or persistence in alternate organs like liver and spleen [17, 36, 37]. Altogether, this illustrates the pluripotency of SL7207. A highly plastic intrinsic ability of tumor colonization described for gram-negative bacteria like the Salmonella strain SL7207 may offer the needed consolidation [70]. As specific bio-vehicles delivery of recombinant immune stimulatory or toxic molecules may complement the intrinsic adjuvant effect, thus providing a more tailored and flexible therapeutic approach [1, 22, 71-73].

Considering that immune therapeutic effects of TNF- $\alpha$ proved exhaustible, and that such may be naturally detrimental, one should place focus on its physiological property rather than immune stimulatory capacity. Our results reinforced the role of TNF- $\alpha$ in tumor invasion [16, 74], and first hand demonstrated its capacity to support colonization with lower infection doses. With an altered strategy in BMTT that focuses on tumor targeting, this synergistic effect may find useful application. Particularly, as a mean to minimize adverse effects like dissemination with higher doses of Salmonella, while ensuring full tumor targeting capacity.

In conclusion, reduction of SL7207 to an endotoxic effect did not prove feasible in tumor models other than CT26. Nevertheless, this model highlighted that a tumor specific CTL response can be stimulated along the LPS/ TLR4 axis alone. Efficient BMTT requires more than an exhaustible adjuvant effect, thus favoring the need for complementary effects through recombinant strengthening. Focus on alternate intrinsic bacterial qualities such as tumor targeting may thus prove essential to prevail as a sustainable type of therapy.

\section{MATERIALS AND METHODS}

\section{Ethics statement}

All animal experiments were performed according to the guidelines of the German Law for Animal Protection and with permission by the local ethics committee and authority LAVES (Niedersächsisches Landesamt für Verbraucherschutz und Lebensmittelsicherheit). The animal permission was issued under number: $33.9-42502-$ 04-12/0713.

\section{Animal models and tumor development}

Six to eight weeks old female BALB/c mice were purchased from Janvier, and $\operatorname{Rag} 1^{-/}$of the same age and gender were made available from our in-house breeding. All mice were kept in IVC cages under SPF conditions. Upon acclimatization, mice received a s.c. injection into the right flank with $5 \times 10^{5} \mathrm{CT} 26$ colon carcinoma cells (ATCC CRL-2638), $1.5 \times 10^{6}$ renal carcinoma (RenCa) cells (ATCC CRL-2947) or $5 \times 10^{5}$ F1.A11 fibro-sarcoma cells (curtesy of Dr. Pablo Becker, HZI, Braunschweig) in $100 \mu \mathrm{l}$ PBS (Supplementary Table 1). Upon 8 and 10 days of development for RenCa and CT26, respectively, having reached tumor sizes of $100-150 \mathrm{~mm}^{3}$, mice were grouped and standardized for mean and variance in tumor volume prior to injection treatments. Tumor development was expressed via volume calculations based on caliper measurements in two dimensions: $\mathrm{V}=\pi / 6 \times \mathrm{h} \times \mathrm{w}^{2}$, wherein "h" = height and "w" = width.

\section{Inoculation procedures}

Salmonella enterica serovar Typhimurium variant SL7207 (his $G^{-}, \triangle$ aroA) [75], was deployed from our in- 
house stock, and E. coli probiotic Symbioflor-2 (DSM 17252), a combination of strains G1/2, G3/10, G4/9, G5, G6/7 and G8 (DSM 16441-16447, resp.) [76], was provided with curtesy of Dr. Kurt Zimmermann, SymbioPharm GmbH. Inoculi were prepared as described in Kocijancic et al. (2016). In short, cultures harvested at mid log phase were washed twice, before adjusted via $\mathrm{OD}_{600}$ to the standard dose of $5 \times 10^{6} / 100 \mu \mathrm{l}$ in pyrogenfree PBS. Preparations of avitalized bacteria were achieved via heat-inactivation at $60^{\circ} \mathrm{C}$ for 1 hour, or UV irradiation exposing the suspension under a laminar flow bench for 2 hours. Plating controls were performed to verify the inocula. Ultimately, bacterial suspensions were administered i.v. via the lateral tail vein at day 0 post infection (0 dpi). For alternate inoculations, LPS from $S$. typhosa and E. coli O55:B5 were purchased from Sigma, and administered i.v. at a dose of $50 \mu \mathrm{g}$, determined as a sublethal dose conversely. Recombinant murine TNF- $\alpha$ (Chemicon) was inoculated i.v. at an effective dose of $1 \mu \mathrm{g} /$ mouse [16].

\section{Bacterial recovery from tissues}

At time points of interest, mice were sacrificed using $\mathrm{CO}_{2}$. Tissues of interest; tumor, spleen and liver, were aseptically isolated and suspended in $1 \mathrm{ml}$ sterile PBS containing $0.1 \%(\mathrm{v} / \mathrm{v})$ Triton $\mathrm{X}-100$. For determination of CFU, tissues were homogenized using a gentleMAX dissociator (Miltenyi Biotec), plated in serial dilutions on selective agar, and incubated $\mathrm{ON}$ at $37^{\circ} \mathrm{C}$.

\section{Measurement of TNF- $\alpha$}

Blood samples were acquired via heart punctuation, or retro-orbital bleeding (kinetics), around the time point 1.5 hpi. Serum was isolated using Microvette serum tubes (Sarstedt) according to manufacturer protocols. Quantification was performed using the bioassay described in Leschner et al. (2009), or the TNF- $\alpha$ specific ELISA Max $^{\mathrm{TM}}$ Standard kit (Biolegend), as specified.

\section{Adoptive transfer experiments}

As highlighted in Figure 2A, spleens were isolated from infected, tumor bearing, or naive $\mathrm{BALB} / \mathrm{c}$ mice. Tissues were disrupted using a cell strainer, and splenocytes were deprived of erythrocytes using ACK lysis buffer. Eventually $\mathrm{CD} 4^{+}$and $\mathrm{CD} 8^{+} \mathrm{T}$ cell populations were purified using negative isolation kits (Invitrogen), and verified using flow cytometry by staining for CD3, CD4, CD8, and CD19. Fractions of transferred T cells contained $<0.3 \%$ B cells, and were clear of opposing $\mathrm{CD}^{+} / \mathrm{CD}^{+} \mathrm{T}$ cell population (data not shown). For reconstitution experiments, $3 \times 10^{6} \mathrm{~T}$ cells were adoptively transferred via i.v. injection into Rag $1^{-/}$recipients.

\section{Histology}

Upon isolation, specimens were fixed with $4 \%(\mathrm{v} / \mathrm{v})$ formalin for $24-48 \mathrm{~h}$, and embedded in paraffin. $3 \mu \mathrm{m}$ thin sections were stained with hematoxylin/ eosin according to standard laboratory procedures. Immune histochemical staining was performed using the following antibodies: rabbit-anti-Ki-67 (Neo Makers, RM-9106-S), rabbit-antipimonidazole (HP3-100 kit, Hydroxyprobe Inc.), rabbitanti-myeloperoxidase (MPO, ThermoScientific) and DAB (3,3-Diaminobenzidine Zytomed Systems DAB530) as chromogen. Hematoxylin was used for counterstaining. Sections were analyzed by light microscopy blinded to the experimental groups.

\section{Statistical analyses}

The non-parametric Mann-Whitney test and oneway analysis of variance (ANOVA) with Bonferroni posttests were used to compare two or more groups, respectively. Significance levels of $p<0.05, p<0.01$, or $p<0.001$ were indicated using asterisks: $*, * *$, and $* * *$, respectively. All results displayed are representative of at least two independent experiments.

\section{ACKNOWLEDGMENTS}

We thank Susanne zur Lage and Regina Lesch for their expert technical assistance.

\section{CONFLICTS OF INTEREST}

The authors declare no conflicts of interest.

\section{GRANT SUPPORT}

The study was supported in part by the Deutsche Krebshilfe, the Bundesministerium für Bildung und Forschung (BMBF), Hannover Biomedical Research School (HBRS), Center for Infection Biology (ZIB) at Hannover Medical School, a Lichtenberg Fellowship from the Niedersächsiche Ministerium für Wissenschaft und Kultur (MWK), and SymbioPharm GmbH.

\section{REFERENCES}

1. Felgner S, Kocijancic D, Frahm M, Weiss S. Bacteria in Cancer Therapy: Renaissance of an Old Concept. Int J Microbiol. 2016; 2016:8451728.

2. Nauts HC. Bacterial pyrogens: beneficial effects on cancer patients. Prog Clin Biol Res. 1982; 107:687-96.

3. Hoption Cann SA, van Netten JP, van Netten C, Glover DW. Spontaneous regression: a hidden treasure buried in time. Med Hypotheses. 2002; 58:115-9. 
4. Coley WB. The Treatment of Inoperable Sarcoma by Bacterial Toxins (the Mixed Toxins of the Streptococcus erysipelas and the Bacillus prodigiosus). Proc R Soc Med. 1910; 3:1-48.

5. Forbes NS. Engineering the perfect (bacterial) cancer therapy. Nat Rev Cancer. 2010; 10:785-94.

6. Zhao M, Yang M, Ma H, Li X, Tan X, Li S, Yang Z, Hoffman RM. Targeted Therapy with a Salmonella Typhimurium Leucine-Arginine Auxotroph Cures Orthotopic Human Breast Tumors in Nude Mice. Cancer Res. 2006; 66:7647-53.

7. Hoffman RM. Tumor-Targeting Salmonella typhimurium A1-R: An Overview. Methods Mol Biol. 2016; 1409:1-8.

8. Hoiseth SK, Stocker BAD. Aromatic-dependent Salmonella Typhimurium are non-virulent and effective as live vaccines. Nature. 1981; 291: 238-9.

9. Clairmont $\mathrm{C}$, Lee $\mathrm{KC}$, Pike J, Ittensohn $\mathrm{M}$, Low $\mathrm{KB}$, Pawelek J, Bermudes D, Brecher SM, Margitich D, Turnier J, Li Z, Luo X, King I, et al. Biodistribution and genetic stability of the novel antitumor agent VNP20009, a genetically modified strain of Salmonella Typhimurium. J Infect Dis. 2000; 181:1996-2002.

10. Toneri M, Miwa S, Zhang Y, Hu C, Yano S, Matsumoto Y, Bouvet M, Nakanishi H, Hoffman RM, Zhao M. Tumortargeting Salmonella typhimurium A1-R inhibits human prostate cancer experimental bone metastasis in mouse models. Oncotarget. 2015; 6:31335-43. doi: 10.18632/ oncotarget.5866.

11. Hayashi K, Zhao M, Yamauchi K, Yamamoto N, Tsuchiya H, Tomita K, Hoffman RM. Cancer metastasis directly eradicated by targeted therapy with a modified Salmonella typhimurium. J Cell Biochem. 2009; 106:992-8.

12. Yam C, Zhao M, Hayashi K, Ma H, Kishimoto H, McElroy M, Bouvet M, Hoffman RM. Monotherapy with a Tumor-Targeting Mutant of $S$. typhimurium Inhibits Liver Metastasis in a Mouse Model of Pancreatic Cancer. J Surg Res. 2010; 164:248-55.

13. Murakami T, Hiroshima Y, Zhao M, Zhang Y, Chishima T, Tanaka K, Bouvet M, Endo I, Hoffman RM. Adjuvant treatment with tumor-targeting Salmonella typhimurium A1-R reduces recurrence and increases survival after liver metastasis resection in an orthotopic nude mouse model. Oncotarget. 2015; 6:41856-62. doi: 10.18632/ oncotarget.6170.

14. Kiyuna T, Murakami T, Tome Y, Kawaguchi K, Igarashi K, Zhang Y, Zhao M, Li Y, Bouvet M, Kanaya F, Singh A, Dry S, Eilber FC, et al. High efficacy of tumor-targeting Salmonella typhimurium A1-R on a doxorubicin- and dactolisib-resistant follicular dendritic-cell sarcoma in a patient-derived orthotopic xenograft PDOX nude mouse model. Oncotarget. 2016; 7:33046-54. doi: 10.18632/ oncotarget.8848.

15. Murakami T, DeLong J, Eilber FC, Zhao M, Zhang Y, Zhang N, Singh A, Russell T, Deng S, Reynoso J, Quan C, Hiroshima Y, Matsuyama R, et al. Tumor-targeting Salmonella typhimurium A1-R in combination with doxorubicin eradicate soft tissue sarcoma in a patientderived orthotopic xenograft (PDOX) model. Oncotarget. 2016; 7:12783-90. doi: 10.18632/oncotarget.7226.

16. Leschner S, Westphal K, Dietrich N, Viegas N, Jablonska J, Lyszkiewicz M, Lienenklaus S, Falk W, Gekara N, Loessner H, Weiss S. Tumor Invasion of Salmonella enterica Serovar Typhimurium Is Accompanied by Strong Hemorrhage Promoted by TNF-alpha. PLoS One. 2009; 4:11.

17. Crull K, Bumann D, Weiss S. Influence of infection route and virulence factors on colonization of solid tumors by Salmonella enterica Serovar Typhimurium. FEMS Immunol Med Microbiol. 2011; 62:75-83.

18. Saltzman DA, Heise CP, Hasz DE, Zebede M, Kelly SM, Curtiss R, Leonard AS, Anderson PM. Attenuated Salmonella Typhimurium Containing Interleukin-2 Decreases MC-38 Hepatic Metastases: A Novel Anti-tumor Agent. Cancer Biother Radiopharm. 1996; 11:145-53.

19. Nemunaitis J, Cunningham C, Senzer N, Kuhn J, Cramm J, Litz C, Cavagnolo R, Cahill A, Clairmont C, Sznol M. Pilot trial of genetically modified, attenuated Salmonella expressing the $E$. coli cytosine deaminase gene in refractory cancer patients. Cancer Gene Ther. 2003; 10:737-44.

20. Zhao M, Yang M, Li XM, Jiang P, Baranov E, Li S, Xu M, Penman S, Hoffman RM, Trump DL. Tumor-targeting bacterial therapy with amino acid auxotrophs of GFPexpressing Salmonella typhimurium. Proc Natl Acad Sci USA. 2005; 102:755-60.

21. Nagakura C, Hayashi $K$, Zhao M, Yamauchi $K$, Yamamoto N, Tsuchiya H, Tomita K, Bouvet M, Hoffman RM. Efficacy of a genetically-modified Salmonella typhimurium in an orthotopic human pancreatic cancer in nude mice. Anticancer Res. 2009; 29:1873-8.

22. St Jean AT, Swofford CA, Panteli JT, Brentzel ZJ, Forbes NS. Bacterial delivery of Staphylococcus aureus $\alpha$-hemolysin causes regression and necrosis in murine tumors. Mol Ther. 2014; 22:1266-74.

23. Beutler B. Tlr4: Central component of the sole mammalian LPS sensor. Curr Opin Immunol. 2000; 12:20-6.

24. Mannel DN, Rosenstreich DL, Mergenhagen SE. Mechanism of lipopolysaccharide-induced tumor necrosis: requirement for lipopolysaccharide-sensitive lymphoreticular cells. Infect Immun. 1979; 24:573-6.

25. Guha M, O'Connell MA, Pawlinski R, Hollis A, McGovern P, Yan SF, Stern D, Mackman N. Lipopolysaccharide activation of the MEK-ERK1/2 pathway in human monocytic cells mediates tissue factor and tumor necrosis factor $\alpha$ expression by inducing Elk-1 phosphorylation and Egr-1 expression. Blood. 2001; 98:1429-39.

26. Ramachandran G. Gram-positive and gram-negative bacterial toxins in sepsis: a brief review. Virulence. 2014; 5:213-8.

27. Bauss F, Dröge W, Männel DN. Tumor necrosis factor mediates endotoxic effects in mice. Infect Immun. 1987; 55:1622-5.

28. Wajant H, Pfizenmaier K, Scheurich P. Tumor necrosis factor signaling. Cell Death Differ. 2003; 10:45-65. 
29. Carswell EA, Old LJ, Kassel RL, Green S, Fiore N, Williamson B. An endotoxin-induced serum factor that causes necrosis of tumors. Proc Natl Acad Sci USA. 1975; 72:3666-70.

30. Lejeune FJ, Liénard D, Matter M, Rüegg C. Efficiency of recombinant human TNF in human cancer therapy. Cancer Immun. 2006; 6:6.

31. van Horssen R, Ten Hagen TLM, Eggermont AMM. TNFalpha in cancer treatment: molecular insights, antitumor effects, and clinical utility. Oncologist. 2006; 11:397-408.

32. Dondossola E, Dobroff AS, Marchiò S, Cardó-Vila M, Hosoya H, Libutti SK, Corti A, Sidman RL, Arap W, Pasqualini R. Self-targeting of TNF-releasing cancer cells in preclinical models of primary and metastatic tumors. PNAS. 2016; 113:2223-8.

33. Kaimala S, Mohamed YA, Nader N, Issac J, Elkord E, Chouaib S, Fernandez-Cabezudo MJ, Al-Ramadi BK. Salmonella-mediated tumor regression involves targeting of tumor myeloid suppressor cells causing a shift to M1-like phenotype and reduction in suppressive capacity. Cancer Immunol Immunother. 2014; 63:587-99.

34. Lee $\mathrm{CH}$, Wu CL, Shiau AL. Toll-like receptor 4 mediates an antitumor host response induced by Salmonella choleraesuis. Clin Cancer Res. 2008; 14:1905-12.

35. Stern C, Kasnitz N, Kocijancic D, Trittel S, Riese P, Guzman CA, Leschner S, Weiss S. Induction of $\mathrm{CD}^{+}$ and $\mathrm{CD}^{+}$anti-tumor effector $\mathrm{T}$ cell responses by bacteria mediated tumor therapy. Int J Cancer. 2015; 137:2019-28.

36. Kocijancic D, Felgner S, Frahm M, Komoll RM, Iljazovic A, Pawar V, Rohde M, Heise U, Zimmermann K, Gunzer F, Hammer J, Crull K, Leschner S, et al. Therapy of solid tumors using probiotic Symbioflor-2 - restraints and potential. Oncotarget. 2016; 7:22605-22. doi: 10.18632/ oncotarget.8027.

37. Frahm M, Felgner S, Kocijancic D, Rohde M, Hensel M, Iii C, Erhardt M, Weiss S. Efficiency of Conditionally Attenuated Salmonella enterica Serovar Typhimurium in Bacterium-Mediated Tumor Therapy. MBio. 2015; 6:1-11.

38. Felgner S, Kocijancic D, Frahm M, Curtiss R, Erhardt M, Weiss S. Optimizing Salmonella enterica serovar Typhimurium for bacteria-mediated tumor therapy. Gut Microbes. 2016; 7:171-7.

39. Kong Q, Yang J, Liu Q, Alamuri P, Roland KL, Curtiss R 3rd. Effect of deletion of genes involved in lipopolysaccharide core and $\mathrm{O}$-antigen synthesis on virulence and immunogenicity of Salmonella enterica Serovar Typhimurium. Infect Immun. 2011; 79:4227-39.

40. Westphal K, Leschner S, Jablonska J, Loessner H, Weiss S. Containment of tumor-colonizing bacteria by host neutrophils. Cancer Res. 2008; 68: 2952-60.

41. Maciag PC, Radulovic S, Rothman J. The first clinical use of a live-attenuated Listeria monocytogenes vaccine: A Phase I safety study of Lm-LLO-E7 in patients with advanced carcinoma of the cervix. Vaccine. 2009; 27: 3975-83.

42. Toso JF, Gill VJ, Hwu P, Marincola FM, Restifo NP, Schwartzentruber DJ, Sherry RM, Topalian SL, Yang JC,
Stock F, Freezer LJ, Morton KE, Seipp C, et al. Phase I study of the intravenous administration of attenuated Salmonella Typhimurium to patients with metastatic melanoma. J Clin Oncol. 2002; 20:142-52.

43. Marigo I, Zilio S, Desantis G, Mlecnik B, Agnellini AHR, Ugel S, Sasso MS, Qualls JE, Kratochvill F, Zanovello P, Molon B, Ries CH, Runza V, et al. T Cell Cancer Therapy Requires CD40-CD40L Activation of Tumor Necrosis Factor and Inducible Nitric-Oxide-Synthase-Producing Dendritic Cells. Cancer Cell. 2016; 30:377-90.

44. Suresh M, Singh A, Fischer C. Role of Tumor Necrosis Factor Receptors in Regulating CD8 T-Cell Responses during Acute Lymphocytic Choriomeningitis Virus Infection. J Virol. 2005; 79:202-13.

45. Klier U, Maletzki C, Göttmann N, Kreikemeyer B, Linnebacher M. Avitalized bacteria mediate tumor growth control via activation of innate immunity. Cell Immunol. 2011; 269:120-7.

46. Yang L, Froio RM, Sciuto TE, Dvorak AM, Alon R, Luscinskas FW, Dc W. ICAM-1 regulates neutrophil adhesion and transcellular migration of TNF- $\alpha$-activated vascular endothelium under flow. Blood. 2012; 106:584-92.

47. Zhang S, Nie S, Huang D, Li W, Xie M. Immunomodulatory effect of Ganoderma atrum polysaccharide on CT26 tumorbearing mice. Food Chem. 2013; 136:1213-9.

48. Yoon W, Choi JH, Kim S, Park YK. Engineered Salmonella typhimurium expressing E7 fusion protein, derived from human papillomavirus, inhibits tumor growth in cervical tumor-bearing mice. Biotechnol Lett. 2014; 36:349-56.

49. Fend L, Remy-Ziller C, Foloppe J, Kempf J, Cochin S, Barraud L, Accart N, Erbs P, Fournel S, Préville X. Oncolytic virotherapy with an armed vaccinia virus in an orthotopic model of renal carcinoma is associated with modification of the tumor microenvironment. Oncoimmunology. 2016; 5:e1080414.

50. Yoon WS, Chae YS, Hong J, Park YK. Antitumor therapeutic effects of a genetically engineered Salmonella typhimurium harboring TNF- $\alpha$ in mice. Appl Microbiol Biotechnol. 2011; 89:1807-19.

51. Ganai S, Arenas RB, Sauer JP, Bentley B, Forbes NS. In tumors Salmonella migrate away from vasculature toward the transition zone and induce apoptosis. Cancer Gene Ther. 2011; 18:457-66.

52. Zhang Y, Zhang Y, Xia L, Zhang X, Ding X, Yan F, Wu F. Escherichia coli Nissle 1917 targets and restrains mouse b16 melanoma and 4T1 breast tumors through expression of azurin protein. Appl Environ Microbiol. 2012; 78:7603-10.

53. Wang S, Kong Q, Curtiss R. New technologies in developing recombinant attenuated Salmonella vaccine vectors. Microb Pathog. 2013; 58:17-28.

54. Gregory AD, Houghton AM. Tumor-associated neutrophils: New targets for cancer therapy. Cancer Res. 2011; 71:2411-6.

55. Fridlender ZG, Sun J, Kim S, Kapoor V, Cheng G, Ling L, Worthen GS, Albelda SM. Polarization of TumorAssociated Neutrophil Phenotype by TGF-b: 'N1' versus 'N2' TAN. Cancer Cell. 2009; 16:183-94. 
56. Wu C, Andzinski L, Kasnitz N, Kröger A, Klawonn F, Lienenklaus S, Weiss S, Jablonska J. The lack of type I interferon induces neutrophil-mediated pre-metastatic niche formation in the mouse lung. Int J Cancer. 2015; 137:837-47.

57. Jablonska J, Wu CF, Andzinski L, Leschner S, Weiss S. CXCR2-mediated tumor-associated neutrophil recruitment is regulated by IFN- $\beta$. Int J Cancer. $2014 ; 134: 1346-58$.

58. Andzinski L, Wu CF, Lienenklaus S, Kröger A, Weiss S, Jablonska J. Delayed apoptosis of tumor associated neutrophils in the absence of endogenous IFN- $\beta$. Int J Cancer. 2015; 136:572-83.

59. Hummel S, Apte RN, Qimron U, Vitacolonna M, Porgador A, Zoller M. Tumor vaccination by Salmonella typhimurium after transformation with a eukaryotic expression vector in mice: impact of a Salmonella typhimurium gene interfering with MHC class I presentation. J Immunother. 2005; 28:467-79.

60. Otto F, Schmid P, Mackensen A, Wehr U, Seiz A, Braun M, Galanos C, Mertelsmann R, Engelhardt R. Phase II trial of intravenous endotoxin in patients with colorectal and nonsmall cell lung cancer. Eur J Cancer. 1996; 32A:1712-8.

61. Danielli R, Patuzzo R, Di Giacomo AM, Gallino G, Maurichi A, Di Florio A, Cutaia O, Lazzeri A, Fazio C, Miracco C, Giovannoni L, Elia G, Neri D, et al. Intralesional administration of L19-IL2/L19-TNF in stage III or stage IVM1a melanoma patients: results of a phase II study. Cancer Immunol Immunother. 2015; 64:999-1009.

62. Chen J, Yang B, Cheng X, Qiao Y, Tang B, Chen G, Wei J, Liu X, Cheng W, Du P, Huang X, Jiang W, Hu Q, et al. Salmonella-mediated tumor-targeting TRAIL gene therapy significantly suppresses melanoma growth in mouse model. Cancer Sci. 2012; 103:325-33.

63. Maeshima N, Fernandez RC. Recognition of lipid A variants by the TLR4-MD-2 receptor complex. Front Cell Infect Microbiol. 2013; 3:3.

64. Zhang H, Niesel DW, Peterson JW, Klimpel GR. Lipoprotein Release by Bacteria: Potential Factor in Bacterial Pathogenesis. Infect Immun. 1998; 66:5196-201.

65. Pearson FC, Weary ME, Sargent HE, Novitsky TJ, Lin H, Lindsay G, Berzofsky RN, Lane AL, Wilson JD, Cooper JF. Comparison of several control standard endotoxins to the National Reference Standard Endotoxin - an HIMA collaborative study. Appl Environ Microbiol. 1985; 50: 91-3.

66. Hurley JC. Endotoxemia: methods of detection and clinical correlates. Clin Microbiol Rev. 1995; 8:268-92.
67. Schreiber F, Kay S, Frankel G, Clare S, Goulding D, van de Vosse E, van Dissel JT, Strugnell R, Thwaites G, Kingsley RA, Dougan G, Baker S. The Hd, Hj, and Hz66 flagella variants of Salmonella enterica serovar Typhi modify host responses and cellular interactions. Sci Rep. 2015; 5:7947.

68. Powell DA, Roberts LM, Ledvina HE, Sempowski GD, Curtiss R 3rd, Frelinger JA. Distinct innate responses are induced by attenuated Salmonella enterica serovar Typhimurium mutants. Cell Immunol. 2016; 299:42-9.

69. Mumm JB, Emmerich J, Zhang X, Chan I, Wu L, Mauze S, Blaisdell S, Basham B, Dai J, Grein J, Sheppard C, Hong K, Cutler C, et al. IL-10 Elicits IFN $\gamma$-Dependent Tumor Immune Surveillance. Cancer Cell. 2011; 20:781-96.

70. Pawelek JM, Low KB, Bermudes D. Bacteria as tumourtargeting vectors. Lancet Oncol. 2003; 4:548-56.

71. Cronin M, Stanton RM, Francis KP, Tangney M. Bacterial vectors for imaging and cancer gene therapy: a review. Cancer Gene Ther. 2012; 19:731-40.

72. Vom Berg J, Vrohlings M, Haller S, Haimovici A, Kulig P, Sledzinska A, Weller M, Becher B. Intratumoral IL-12 combined with CTLA-4 blockade elicits T cell-mediated glioma rejection. J Exp Med. 2013; 210:2803-11.

73. Berger E, Soldati R, Huebener N, Hohn O, Stermann A, Durmus T, Lobitz S, Zenclussen AC, Christiansen H, Lode HN, Fest S. Salmonella SL7207 application is the most effective DNA vaccine delivery method for successful tumor eradication in a murine model for neuroblastoma. Cancer Lett. 2013; 331:167-73.

74. Drees JJ, Mertensotto MJ, Augustin LB, Schottel JL, Saltzman DA. Vasculature Disruption Enhances Bacterial Targeting of Autochthonous Tumors. J Cancer. 2015; 6: 843-8.

75. Edwards MF, Stocker BA. Construction of delta aroA his delta pur strains of Salmonella typhi. J Bacteriol. 1988; 170: 3991-5.

76. Wassenaar TM, Zschüttig A, Beimfohr C, Geske T, Auerbach C, Cook H, Zimmermann K, Gunzer F. Virulence genes in a probiotic $E$. coli product with a recorded long history of safe use. Eur J Microbiol Immunol. 2015; 5:81-93.

77. Crull K, Weiss S. Antibiotic control of tumor-colonizing Salmonella enterica Serovar Typhimurium. Exp Biol Med. 2011; 236:1282-90. 